\title{
2011s-27
}

\section{Measuring High-Frequency Causality Between Returns, Realized Volatility and Implied Volatility}

\author{
Jean-Marie Dufour, René Garcia, Abderrahim Taamouti
}

\begin{tabular}{c}
\hline Série Scientifique \\
Scientific Series
\end{tabular}

\section{Montréal}

Février 2011

(C) 2011 Jean-Marie Dufour, René Garcia, Abderrahim Taamouti. Tous droits réservés. All rights reserved. Reproduction partielle permise avec citation du document source, incluant la notice $\mathbb{C}$.

Short sections may be quoted without explicit permission, if full credit, including (C) notice, is given to the source.
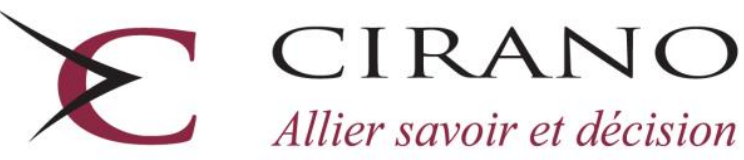

Allier savoir et décision

Centre interuniversitaire de recherche en analyse des organisations 


\section{CIRANO}

Le CIRANO est un organisme sans but lucratif constitué en vertu de la Loi des compagnies du Québec. Le financement de son infrastructure et de ses activités de recherche provient des cotisations de ses organisations-membres, d'une subvention d'infrastructure du Ministère du Développement économique et régional et de la Recherche, de même que des subventions et mandats obtenus par ses équipes de recherche.

CIRANO is a private non-profit organization incorporated under the Québec Companies Act. Its infrastructure and research activities are funded through fees paid by member organizations, an infrastructure grant from the Ministère du Développement économique et régional et de la Recherche, and grants and research mandates obtained by its research teams.

\section{Les partenaires du CIRANO}

Partenaire majeur

Ministère du Développement économique, de l'Innovation et de l'Exportation

\section{Partenaires corporatifs}

Banque de développement du Canada

Banque du Canada

Banque Laurentienne du Canada

Banque Nationale du Canada

Banque Royale du Canada

Banque Scotia

Bell Canada

BMO Groupe financier

Caisse de dépôt et placement du Québec

Fédération des caisses Desjardins du Québec

Financière Sun Life, Québec

Gaz Métro

Hydro-Québec

Industrie Canada

Investissements PSP

Ministère des Finances du Québec

Power Corporation du Canada

Raymond Chabot Grant Thornton

Rio Tinto

State Street Global Advisors

Transat A.T.

Ville de Montréal

\section{Partenaires universitaires}

École Polytechnique de Montréal

HEC Montréal

McGill University

Université Concordia

Université de Montréal

Université de Sherbrooke

Université du Québec

Université du Québec à Montréal

Université Laval

Le CIRANO collabore avec de nombreux centres et chaires de recherche universitaires dont on peut consulter la liste sur son site web.

Les cahiers de la série scientifique (CS) visent à rendre accessibles des résultats de recherche effectuée au CIRANO afin de susciter échanges et commentaires. Ces cahiers sont écrits dans le style des publications scientifiques. Les idées et les opinions émises sont sous l'unique responsabilité des auteurs et ne représentent pas nécessairement les positions du CIRANO ou de ses partenaires.

This paper presents research carried out at CIRANO and aims at encouraging discussion and comment. The observations and viewpoints expressed are the sole responsibility of the authors. They do not necessarily represent positions of CIRANO or its partners. 


\title{
Measuring High-Frequency Causality Between Returns, Realized Volatility and Implied Volatility
}

\author{
Jean-Marie Dufour ${ }^{\dagger}$, Réné Garcia ${ }^{*}$,Abderrahim Taamouti ${ }^{\S}$
}

\begin{abstract}
In this paper, we provide evidence on two alternative mechanisms of interaction between returns and volatilities: the leverage effect and the volatility feedback effect. We stress the importance of distinguishing between realized volatility and implied volatility, and find that implied volatilities are essential for assessing the volatility feedback effect. The leverage hypothesis asserts that return shocks lead to changes in conditional volatility, while the volatility feedback effect theory assumes that return shocks can be caused by changes in conditional volatility through a time-varying risk premium. On observing that a central difference between these alternative explanations lies in the direction of causality, we consider vector autoregressive models of returns and realized volatility and we measure these effects along with the time lags involved through short-run and long-run causality measures proposed in Dufour and Taamouti (2010), as opposed to simple correlations. We analyze 5-minute observations on S\&P 500 Index futures contracts, the associated realized volatilities (before and after filtering jumps through the bispectrum) and implied volatilities. Using only returns and realized volatility, we find a strong dynamic leverage effect over the first three days. The volatility feedback effect appears to be negligible at all horizons. By contrast, when implied volatility is considered, a volatility feedback becomes apparent, whereas the leverage effect is almost the same. These results can be explained by the fact that volatility feedback effect works through implied volatility which contains important information on future volatility, through its nonlinear relation with option prices which are themselves forward-looking. In addition, we study the dynamic impact of news on returns
\end{abstract}

\footnotetext{
* This paper was previously circulating under the title "Measuring causality between volatility and returns with highfrequency data". The authors thank Ryan Compton, Robert Engle, Luc Bauwens, Benoit Perron, two anonymous referees, and the Co-Editor George Tauchen for several useful comments. Earlier versions of this paper were presented at the NBER-NSF Time Series Conference inMontr'eal (2006), the Conference on Volatility and High Frequency Data at Chicago (2007), the 47th Annual Meeting of the Société canadienne de science économique in Québec city (2007), the 41th Annual Meeting of the Canadian Economics Association at Halifax (2007), the 13th International Conference on Computing in Economics and Finance at Montréal (2007), the Tenth Annual Financial Econometrics Conference at Waterloo (2008), CORE seminar, Humboldt-Copenhagen Conference (2009), North American Summer Meeting of the Econometric Society (2009) and the 2009 European meeting of the Econometric Society (ESEM). This work was supported by theWilliam Dow Chair in Political Economy (McGill University), the Canada Research Chair Program (Chair in Econometrics, Université deMontréal), the Bank of Canada (Research Fellowship), a Guggenheim Fellowship, a Konrad-Adenauer Fellowship (Alexander-vonHumboldt Foundation, Germany), the Institut de finance mathématique de Montréal (IFM2), the Canadian Network of Centres of Excellence [program on Mathematics of Information Technology and Complex Systems (MITACS)], the Natural Sciences and Engineering Research Council of Canada, the Social Sciences and Humanities Research Council of Canada, and the Fonds de recherche sur la société et la culture (Québec). Financial support from the Spanish Ministry of Education through grants SEJ 2007-63098 is acknowledged.

${ }^{\dagger}$ William Dow Professor of Economics, McGill University, CIRANO and CIREQ. Department of Economics, McGill University, Leacock Building, Room 519, 855 Sherbrooke Street West, Montréal, Québec H3A 2T7, Canada. TEL: (1) 514 398 8879; FAX: (1) 514398 4938; e-mail: jean-marie.dufour@ mcgill.ca. Webpage: http://www.jeanmariedufour.com ${ }^{\ddagger}$ Edhec Business School, CIRANO and CIREQ. Edhec Business School, 393, Promenade des Anglais, BP 3116,06202 Nice Cedex 3, France. TEL: +33(0)493187802; FAX: +33(0)493187841; e-mail: rene.garcia@edhec.edu.

${ }^{\S}$ Economics Department, Universidad Carlos III de Madrid, Departamento de Economía, Calle Madrid, 12628903 Getafe (Madrid) España. TEL: +34-91 6249863; FAX: +34-91 6249329; e-mail: ataamout@eco.uc3m.es.
} 
and volatility. First, to detect possible dynamic asymmetry, we separate good from bad return news and find a much stronger impact of bad return news (as opposed to good return news) on volatility. Second, we introduce a concept of news based on the difference between implied and realized volatilities (the variance risk premium) and we find that a positive variance risk premium (an anticipated increase in variance) has more impact on returns than a negative variance risk premium.

Mots-clés : Volatility asymmetry, leverage effect, volatility feedback effect, risk premium, variance risk premium, multi-horizon causality, causality measure, highfrequency data, realized volatility, bipower variation, implied volatility.

JEL codes: G1, G12, G14, C1, C12, C15, C32, C51, C53. 


\section{Introduction}

One of the many stylized facts about equity returns is an asymmetric relationship between returns and volatility. Volatility tends to rise following negative returns and falls following positive returns. Two main explanations for volatility asymmetry have been proposed in the literature. The first one is the leverage effect. While the term was originally coined with respect to financial leverage of a firm [see Black (1976) and Christie (1982)], it refers today to a negative correlation between lagged returns and current volatility. ${ }^{1}$ The second explanation is the volatility feedback effect, which is related to a time-varying risk premium: if volatility is priced, an anticipated increase in volatility raises the required rate of return, implying an immediate stock price decline in order to allow for higher future returns; see Pindyck (1984), French, Schwert and Stambaugh (1987), Campbell and Hentschel (1992), and Bekaert and Wu (2000).

In this paper, we provide new evidence on these two interaction mechanisms between returns and volatilities by considering causality measures on high-frequency data. We also stress the importance of distinguishing between realized volatility and implied volatility when studying leverage and volatility feedback effects, and we find that implied volatilities are essential for detecting and assessing the volatility feedback effect.

On noting that the two explanations involve different causal mechanisms [see Bekaert and Wu (2000) and Bollerslev et al. (2006)], which may differ both through their direction and the time lags involved, we study the issue using short and long-run causality measures recently introduced in Dufour and Taamouti (2010). The causality measures allow us to study and test the asymmetric volatility phenomena at several horizons. When considering horizons longer than one period, it is important to account for indirect causality. Auxiliary variables can transmit causality between two variables of interest at horizons strictly higher than one, even if there is no causality between the two variables at the horizon one; see Dufour and Renault (1998) and Dufour, Pelletier and Renault (2006). Using high-frequency data increases the chance to detect causal links since aggregation may make the relationship between returns and volatility simultaneous. By relying on realized volatility measures, we avoid the need to specify a volatility model.

To be more explicit on the causality issue involved, the leverage effect explains why a negative return shock leads to higher subsequent volatility, while the volatility feedback effect explains how an anticipated increase in volatility may result in a negative return. Thus, volatility asymmetry may result from various causal links: from returns to volatility, from volatility to returns, instantaneous causality. Causality here is defined as in Granger (1969): a variable $Y$ causes a variable $X$ if the variance of the forecast error of $X$ obtained by using the past of $Y$ is smaller than the variance of the forecast error of $X$ obtained without using the past of $Y$.

Concerning terminology, it is worthwhile pointing out that some authors may prefer to use terms like "predictibility" or "linear predictibility", instead of "causality". There is however a long philosophical

\footnotetext{
${ }^{1}$ The concept of leverage effect was introduced to explain this negative correlation by the fact that a decrease in the price of a firm increases financial leverage and the probability of bankruptcy, making the asset riskier, hence an increase in volatility. Today the concept of dynamic leverage effect applies directly to stock market indices, without any rooting in changes of financial leverage; see Bouchaud, Matacz and Potters (2001), Jacquier, Polson and Rossi (2004), Brandt and Kang (2004), Ludvigson and Ng (2005), Bollerslev, Litvinova and Tauchen (2006), and Bollerslev, Sizova and Tauchen (2009).
} 
tradition which reduces the concept of "causality" to the notion of "predictibility". This tradition goes back at least to Hume (1748) and includes numerous authors such as Carnap (1966), Feigl (1953), Salmon (1984) and Eells (1991). Whether there can be an empirically meaningful notion of causality that goes beyond a notion based on predictibility remains highly debatable. Here we take the view that "causality" can only be defined with respect to a particular model [e.g., a vector autoregressive model] which involves specifying a set of variables some of which are classified as "endogenous" and other ones as "predetermined". In order to study "causation" issues with empirical data, it is necessary to specify a limited information set - a point quite explicit in Dufour and Renault (1998). There is no "absolute" (model-free) causation. This means that causality properties may change as the information set is modified (which includes changing data frequency and aggregation).

Further, the clearest criterion for classifying a variable as "predetermined" at a given date is the fact that it can be viewed as determined in the past (on the basis of the principle that the future cannot cause the past). Causality is then a predictibility property of the "endogenous" variables by "predetermined" variables. The notions of "causality" introduced by Wiener (1956) and Granger (1969) as well as their variants provide operational definitions of causality based on these ideas. Occasionally, a property of "Granger causality (or non-causality)" may be interpreted as "spurious", but this simply means that a different model or information set is considered. Such a situation illustrates the fact that "causality" can only be defined with respect to a given model and information set. Irrespective of the latter, one can always argue that "hidden" variables are driving the system, so variables which appear to Granger-cause other ones are simply reflecting "expectations" driven by hidden variables. This can easily be the case in finance and macroeconomics, where expectations typically constitute unobservable variables. The investigator may try to sort this out by introducing such unobserved variables (if reasonable measures or proxies can be obtained): this amounts to enlarging the information set, and our may in turn be used with the new information. Note however that the "hidden variable criticism" may endlessly be reapplied, since empirically usable information sets are always finite. In any case, demonstrating a Granger-causal structure provides useful information because it shows that either a "mechanism" or an "expectation phenomenon" is sufficiently important to allow forecasting. Further, in financial markets, expectations often determine actions (such as investment decisions) and so may have "effects" that go far beyond the mind-set of financial actors. ${ }^{2}$

In this paper, we stress that statistical tests of the null hypothesis of non-causality (in the sense of Wiener-Granger) constitute a poor way of analyzing causal structures. For example, we can distinguish between causal directions (from $X$ to $Y$, from $Y$ to $X$, instantaneous causality) and causality at different horizons. Different causality relations may coexist, but their relative importance may greatly differ. This suggests of finding means to quantify their degrees. Causality tests fail to accomplish this task, because they only provide evidence on the presence or the absence of causality, and statistical significance depends on the available data and test power. A large effect may not be statistically significant (at a given level), and a

\footnotetext{
${ }^{2}$ For further discussion of causality concepts, the reader may consult Aigner and Zellner (1988), Bunge (1979), Eells (1991), Pearl (2000), Salmon (1984), Spirtes, Glymour and Scheines (1993), Sosa and Tooley (1993).
} 
statistically significant effect may not be "large" from an economic viewpoint (or more generally from the viewpoint of the subject at hand) or relevant for decision making. ${ }^{3}$

In order to quantify and compare the strength of dynamic leverage and volatility feedback effects, we propose to use vector autoregressive (VAR) models of returns and various measures of volatility at high frequency together with short and long-run causality measures in Dufour and Taamouti (2010). For further discussion of the usefulness of causality measures and what they accomplish beyond Granger causality tests, we refer the reader to Dufour and Taamouti (2010).

Using 5-minute observations on S\&P 500 Index futures contracts, we first consider causality measures based on a bivariate VAR involving returns and realized volatility. In this setting, we find a weak dynamic leverage effect for the first four hours in hourly data and a strong dynamic leverage effect for the first three days in daily data. The volatility feedback effect appears to be negligible, irrespective of the horizon considered.

Recently, using high-frequency data and simple correlations, Bollerslev et al. (2006) found an important negative correlation between volatility and (current and lagged) returns lasting for several days, while correlations between returns and lagged volatility are all close to zero. We differ from their study by using short and long-run causality measures to quantify causality at different horizons. The difference between simple correlations and impulse-response functions at horizons greater than one is due to indirect causal effects, as shown in Dufour and Renault (1998). ${ }^{4}$

In studying the relationship between volatility and returns, implied volatility - derived from option prices - can be an interesting alternative measure of volatility or constitutes a useful auxiliary variable, because option prices may capture anticipative additional relevant information as well as nonlinear relations. Thus, implied volatility can be viewed as a forward-looking measure of volatility with an horizon corresponding to the maturity of the option. We find that adding implied volatility to the information set leads to statistical evidence for a sizable volatility feedback effect for a few days, whereas the leverage effect remains almost the same. A key element of the volatility feedback mechanism is an increase of expected future volatility. Implied volatility certainly provides an option market forecast of future volatility, which is better than a forecast based on past realized volatility. ${ }^{5}$

This finding can be contrasted with the one of Masset and Wallmeier (2010), who also used highfrequency data to analyze the lead-lag relationship of option implied volatility and index return in Germany, using Granger causality tests (at horizon one) and impulse-response functions. They find that the relationship is return-driven in the sense that index returns Granger cause volatility changes. Instead, through a more

\footnotetext{
${ }^{3}$ For further discussion of this issue, see McCloskey and Ziliak (1996).

${ }^{4}$ Bollerslev, Kretschmer, Pigorsch and Tauchen (2009) further decompose realized volatility into two components, the continuous-path measure of volatility and the discontinuous jump component. Their results suggest that the leverage effect works primarily through the continuous volatility component.

${ }^{5}$ The informational content of implied volatility does not come as a surprise since several studies have documented that implied volatility can be used to predict whether a market is likely to move higher or lower and help to predict future volatility; see Day and Lewis (1992), Canina and Figlewski (1993), Lamoureux and Lastrapes (1993), Fleming (1998), Poteshman (2000), Blair, Poon and Taylor (2001), and Busch, Christensen and Nielsen (2010). Pooling the information contained in futures and options markets unveils an effect that cannot be found with one market alone.
} 
complete analysis based on the concept of causality at different horizons, we find that implied volatilities are important for assessing the volatility feedback effect. Our result is however broadly consistent with Bollerslev and Zhou (2005), who provide a model-based rationalization for finding such evidence on the volatility feedback effect through implied volatility. Based on a stochastic volatility model, they show that the relation between returns and implied volatility remains positive for all reasonable configurations of parameters.

Another contribution of this paper consists in showing that the proposed causality measures help to quantify the dynamic impact of bad and good return news on volatility. ${ }^{6}$ A common approach to visualize the relationship between news and volatility is provided by the news-impact curve originally studied by Pagan and Schwert (1990) and Engle and Ng (1993). To study the effect of current return shocks on future expected volatility, Engle and $\mathrm{Ng}$ (1993) introduced the News Impact Function (hereafter NIF). The basic idea of this function is to consider the effect of the return shock at time $t$ on volatility at time $t+1$, while conditioning on information available at time $t$ and earlier. Engle and $\mathrm{Ng}$ (1993) explain that this curve, where all the lagged conditional variances are evaluated at the level of the asset return unconditional variance, relates past positive and negative returns to current volatility.

We propose a new curve, the Causal News Impact Function (CNIF), for capturing the impact of news on volatility based on causality measures. In contrast with the NIF of Engle and $\mathrm{Ng}$ (1993), the CNIF curve can be constructed for parametric and stochastic volatility models, and it allows one to consider all the past information about volatility and returns. We also build confidence intervals using a bootstrap technique around the CNIF curve. Further, we can visualize the impact of news on volatility at different horizons [see also Chen and Ghysels (2010)] rather than only one horizon as in Engle and Ng (1993).

We confirm by simulation that the CNIF based on causality measures detects well the differential effect of good and bad news in various parametric volatility models. Then, we apply the concept to the S\&P 500 Index futures returns and volatility: we find a much stronger impact from bad news at several horizons. Statistically, the impact of bad news is significant for the first four days, whereas the impact of good news is negligible at all horizons.

Our results on the informational value of implied volatility also suggest that the difference between implied and realized volatility (called the variance risk premium) constitutes an interesting measure of "news" coming to the market. So we compute causality measures from positive and negative variance risk premia to returns. We find a stronger impact when the difference is positive (an anticipated increase in volatility or bad news) than when it is negative.

Clearly, none of the earlier studies on the relationship between returns and volatility has exploited the new methodology proposed in this paper. But our results nicely complement those of Bollerslev, Tauchen and Zhou (2009) and Bollerslev, Sizova and Tauchen (2009). Using high-frequency intraday returns on the

\footnotetext{
${ }^{6}$ In this study, bad and good news are determined by negative and positive innovations in returns and volatility. The impact of macroeconomic news announcements on financial markets (e.g. volatility) has also been studied by several authors; see Schwert (1981), Pearce and Roley (1985), Hardouvelis (1987), Haugen, Talmor and Torous (1991), Jain (1988), McQueen and Roley (1993), Balduzzi, Elton and Green (2001), Andersen, Bollerslev, Diebold and Vega (2003), and Huang (2007).
} 
S\&P500 index and the VIX volatility index, Bollerslev, Tauchen and Zhou (2009) show that the variance risk premium is able to explain a nontrivial fraction of the time-series variation in post-1990 aggregate stock market returns, with high (low) premia predicting high (low) future returns, at a quarterly frequency. They also observe it is consistent with the predictions of a long-run volatility risk equilibrium model. Bollerslev, Sizova and Tauchen (2009) rely on an equilibrium continuous-time model to capture this fact as well as the asymmetry in the relationship between volatility and past and future returns (leverage and volatility feedback effects).

Other empirical studies on the link between returns and volatility are based on lower-frequency data or model-based measures of volatility; see Christie (1982), French et al. (1987), Schwert (1989), Turner, Startz and Nelson (1989), Nelson (1991), Glosten, Jagannathan and Runkle (1993) and Campbell and Hentschel (1992), Bekaert and Wu (2000), Whaley (2000), Ghysels, Santa-Clara and Valkanov (2004), Giot (2005), Ludvigson and Ng (2005), Dennis, Mayhew and Stivers (2006), and Guo and Savickas (2006) among others. On the relationship and the relative importance of the leverage and volatility feedback effects, the results of this literature are often ambiguous, if not contradictory. In particular, studies focusing on the leverage hypothesis conclude that the latter cannot completely account for changes in volatility; see Christie (1982) and Schwert (1989). However, for the volatility feedback effect, empirical findings conflict. French et al. (1987), Campbell and Hentschel (1992) and Ghysels et al. (2004) find a positive relation between volatility and expected returns, while Turner et al. (1989), Glosten et al. (1993) and Nelson (1991) find a negative relation. From individual-firm data, Bekaert and $\mathrm{Wu}$ (2000) conclude that the volatility feedback effect dominates the leverage effect empirically. The coefficient linking volatility to returns is often not statistically significant. Ludvigson and $\mathrm{Ng}$ (2005) find a strong positive contemporaneous relation between the conditional mean and conditional volatility and a strong negative lag-volatility-in-mean effect. Guo and Savickas (2006) conclude that the stock market risk-return relation is positive, as stipulated by the CAPM; however, idiosyncratic volatility is negatively related to future stock market returns. Giot (2005) and Dennis et al. (2006) use lower frequency data (such as, daily data) to study the relationship between returns and implied volatility. Giot (2005) uses the S\&P 100 index and an implied volatility index (VIX) to show that there is a contemporaneous asymmetric relationship between S\&P 100 index returns and VIX: negative S\&P 100 index returns yield bigger changes in VIX than do positive returns [see Whaley (2000)]. Dennis et al. (2006), using daily stock returns and innovations in option-derived implied volatilities, show that the relation between stock returns and innovations in systematic volatility (idiosyncratic volatility) is substantially negative (near zero).

The plan of the paper is as follows. In Section 2, we define volatility measures in high-frequency data and we review the concept of causality at different horizons and its measures. In Section 3, we propose and discuss VAR models that allow us to measure leverage and volatility feedback effects with high-frequency data. In Section 4, we introduce information implied volatility $(I V)$ - in addition to realized volatility and returns - to measure the dynamic leverage and volatility feedback effects. Section 5 describes the highfrequency data, the estimation procedure and the empirical findings regarding causality effects between 
volatility and returns. In Section 6, we propose a method to assess the dynamic impact of good and bad return news on volatility. Simulation results on the efficiency of this method are also presented. Our empirical results on news effects in S\&P 500 futures market appear in Section 7. We conclude in Section 8. Tables and figures are gathered in appendix.

\section{Volatility and causality measures}

To assess causality between volatility and returns at high frequency, we need to build measures for both volatility and causality. For volatility, we use various measures of realized volatility introduced by Andersen, Bollerslev and Diebold (2010); see also Andersen and Bollerslev (1998), Andersen, Bollerslev, Diebold and Labys (2001), Barndorff-Nielsen and Shephard (2002a), and Barndorff-Nielsen and Shephard (2002b). For causality, we rely on the short and long run causality measures proposed by Dufour and Taamouti (2010).

Let us first set some notations. We denote by $p_{t}$ the logarithmic price of the risky asset or portfolio (at time $t$ ) and by $r_{t+1}=p_{t+1}-p_{t}$ the continuously compounded return from time $t$ to $t+1$. We assume that the price process may exhibit both stochastic volatility and jumps. It could belong to the class of continuous-time jump diffusion processes,

$$
d p_{t}=\mu_{t} d t+\sigma_{t} d W_{t}+\kappa_{t} d q_{t}, 0 \leq t \leq T
$$

where $\mu_{t}$ is a continuous and locally bounded variation process, $\sigma_{t}$ is the stochastic volatility process, $W_{t}$ denotes a standard Brownian motion, $d q_{t}$ is a counting process such that $d q_{t}=1$ represents a jump at time $t$ (and $d q_{t}=0$ no jump) with jump intensity $\lambda_{t}$. The parameter $\kappa_{t}$ refers to the size of the corresponding jumps. Thus, the quadratic variation of returns from time $t$ to $t+1$ is given by

$$
[r, r]_{t+1}=\int_{t}^{t+1} \sigma_{s}^{2} d s+\sum_{0<s \leq t} \kappa_{s}^{2}
$$

where the first component, called integrated volatility, comes from the continuous component of (2.1), and the second term is the contribution from discrete jumps. In the absence of jumps, the second term on the right-hand-side disappears, and the quadratic variation is simply equal to the integrated volatility.

\subsection{Volatility in high-frequency data: realized volatility, bipower variation, jumps}

In this section, we define the high-frequency measures that we shall use to capture volatility. In what follows, we normalize the daily time-interval to unity and we divide it into $h$ periods. Each period has length $\Delta=1 / h$. Let the discretely sampled $\Delta$-period returns be denoted by $r_{(t, \Delta)}=p_{t}-p_{t-\Delta}$ and the

daily return by $r_{t+1}=\sum_{j=1}^{h} r_{(t+j . \Delta, \Delta)}$. The daily realized volatility is defined as the summation of the corresponding $h$ high-frequency intradaily squared returns:

$$
R V_{t+1} \equiv \sum_{j=1}^{h} r_{(t+j \Delta, \Delta)}^{2} .
$$


The realized volatility satisfies

$$
\lim _{\Delta \rightarrow 0} R V_{t+1}=\int_{t}^{t+1} \sigma_{s}^{2} d s+\sum_{0<s \leq t} \kappa_{s}^{2},
$$

which means that $R V_{t+1}$ is a consistent estimator of the sum of the integrated variance $\int_{t}^{t+1} \sigma_{s}^{2} d s$ and the jump contribution; see Andersen and Bollerslev (1998), Andersen, Bollerslev, Diebold and Labys (2001), Andersen et al. (2010), Barndorff-Nielsen and Shephard (2002a, 2002b), and Comte and Renault (1998). ${ }^{7}$ Similarly, a measure of standardized bipower variation is given by

$$
B V_{t+1} \equiv \frac{\pi}{2} \sum_{j=2}^{h}\left|r_{(t+j \Delta, \Delta)}\right|\left|r_{(t+(j-1) \Delta, \Delta)}\right| .
$$

Under reasonable assumptions on the dynamics of (2.1), the bipower variation satisfies

$$
\lim _{\Delta \longrightarrow 0} B V_{t+1}=\int_{t}^{t+1} \sigma_{s}^{2} d s
$$

see Barndorff-Nielsen and Shephard (2004) and Barndorff-Nielsen, Graversen, Jacod, Podolskij and Shephard (2005). Equation (2.3) means that $B V_{t+1}$ provides a consistent estimator of the integrated variance unaffected by jumps. Finally, as noted by Barndorff-Nielsen and Shephard (2004), combining the results in equation (2.2) and (2.3), the contribution to the quadratic variation due to discontinuities (jumps) in the underlying price process may be consistently estimated by

$$
\lim _{\Delta \longrightarrow 0}\left(R V_{t+1}-B V_{t+1}\right)=\sum_{0<s \leq t} \kappa_{s}^{2}
$$

We can also define the relative measure

$$
R J_{t+1}=\frac{\left(R V_{t+1}-B V_{t+1}\right)}{R V_{t+1}}
$$

or the corresponding logarithmic ratio

$$
\bar{J}_{t+1}=\ln \left(R V_{t+1}\right)-\ln \left(B V_{t+1}\right) .
$$

Huang and Tauchen (2005) argue that these are more robust measures of the contribution of jumps to total price variation. Since in practice $J_{t+1}$ can be negative in a given sample, we impose a non-negativity truncation of the actual empirical jump measurements:

$$
J_{t+1} \equiv \max \left[\ln \left(R V_{t+1}\right)-\ln \left(B V_{t+1}\right), 0\right] ;
$$

see Andersen et al. (2010) and Barndorff-Nielsen and Shephard (2004).

\footnotetext{
${ }^{7}$ For a general discussion of integrated and realized volatilities in the absence of jumps, see Meddahi (2002).
} 


\subsection{Short-run and long-run causality measures}

We study causality at different horizons between returns $\left(r_{t}\right)$ and volatilities $\left(\sigma_{t}^{2}\right)$. For that purpose, it will be convenient to define first noncausality in terms of orthogonality between subspaces of a Hilbert space of random variables with finite second moments. To give a formal definition of noncausality at different horizons, we need to consider the following notations. We denote by $r(\omega, t], \sigma^{2}(\omega, t]$, and $z(\omega, t]$ the information contained in the history of variables of interest $r$ and $\sigma^{2}$ and another auxiliary variable $z$ respectively up to time $t$. The "starting point" $\omega$ is typically equal to a finite initial date (such as $\omega=-1,0$ or 1 ) or to $-\infty$. In our empirical application the auxiliary variable $z$ is given by the implied volatility (hereafter $I V$ ). The information sets obtained by "adding" $z(\omega, t]$ to $r(\omega, t], z(\omega, t]$ to $\sigma^{2}(\omega, t], r(\omega, t]$ to $\sigma^{2}(\omega, t]$, and $z(\omega, t]$ to $r(\omega, t]$ and $\sigma^{2}(\omega, t]$ are defined as follows:

$$
\begin{gathered}
I_{r z}(t)=I_{0}+r(\omega, t]+z(\omega, t], I_{\sigma^{2} z}(t)=I_{0}+\sigma^{2}(\omega, t]+z(\omega, t], \\
I_{r \sigma^{2}}(t)=I_{0}+r(\omega, t]+\sigma^{2}(\omega, t], I_{r \sigma^{2} z}(t)=I_{0}+r(\omega, t]+\sigma^{2}(\omega, t]+z(\omega, t],
\end{gathered}
$$

where $I_{0}$ represents a fundamental information set available in all cases (such as deterministic variables, a constant, etc.). Finally, for any given information set $B_{t}$ [some Hilbert subspace] and positive integer $h$, we denote by $P\left[r_{t+h} \mid B_{t}\right]$ (respectively $P\left[\sigma_{t+h}^{2} \mid B_{t}\right]$ ) the best linear forecast of $r_{t+h}$ (respectively $\left.\sigma_{t+h}^{2}\right)$ based on the information set $B_{t}$ and $u\left[r_{t+h} \mid B_{t}\right]=r_{t+h}-P\left[r_{t+h} \mid B_{t}\right]$ (respectively $u\left[\sigma_{t+h}^{2} \mid\right.$ $\left.\left.B_{t}\right]=\sigma_{t+h}^{2}-P\left[\sigma_{t+h}^{2} \mid B_{t}\right]\right)$ the corresponding prediction error. ${ }^{8}$ Thus, we have the following definition of noncausality at different horizons [see Dufour and Renault (1998) and Dufour and Taamouti (2010)].

Definition 2.1 Let $h$ be a positive integer.

(i) $r$ does not cause $\sigma^{2}$ at horizon h given $I_{\sigma^{2} z}(t)$, denoted $r \underset{h}{\nrightarrow} \sigma^{2} \mid I_{\sigma^{2} z}(t)$, iff

$$
\operatorname{Var}\left[u\left[\sigma_{t+h}^{2} \mid I_{\sigma^{2} z}(t)\right]\right]=\operatorname{Var}\left[u\left[\sigma_{t+h}^{2} \mid I_{r \sigma^{2} z}(t)\right]\right]
$$

(ii) $r$ does not cause $\sigma^{2}$ up to horizon $h$ given $I_{\sigma^{2} z}(t)$, denoted $r \underset{(h)}{\stackrel{(}{)}} \sigma^{2} \mid I_{\sigma^{2} z}(t)$, iff

$$
r \underset{k}{\stackrel{\leftrightarrow}{\leftrightarrow}} \sigma^{2} \mid I_{\sigma^{2} z}(t) \text { for } k=1,2, \ldots, h ;
$$

(iii) $r$ does not cause $\sigma^{2}$ at any horizon given $I_{\sigma^{2} z}(t)$, denoted $\underset{(\infty)}{\stackrel{\leftrightarrow}{(\infty)}} \sigma^{2} \mid I_{\sigma^{2} z}(t)$, iff

$$
r \underset{k}{\stackrel{\leftrightarrow}{a}} \sigma^{2} \mid I_{\sigma^{2} z}(t) \text { for all } k=1,2, \ldots
$$

Definition 2.1 corresponds to causality from $r$ to $\sigma^{2}$ and means that $r$ causes $\sigma^{2}$ at horizon $h$ if the past of $r$ improves the forecast of $\sigma_{t+h}^{2}$ given the information set $I_{\sigma^{2} z}(t)$. We can similarly define noncausality at horizon $h$ from $\sigma^{2}$ to $r$. The presence of the auxiliary variable $z$ may transmit causality between $r$ and $\sigma^{2}$ at horizon $h$ strictly higher than one, even if there is no causality between the two variables at horizon 1 .

\footnotetext{
${ }^{8} B_{t}$ can be equal to $I_{r \sigma z}(t), I_{r z}(t)$, or $I_{\sigma z}(t)$.
} 
However, in the absence of auxiliary variable, noncausality at horizon 1 implies noncausality at any horizon $h$ strictly higher than one; see Dufour and Renault (1998). In other words,

$$
\begin{gathered}
r \underset{1}{\nrightarrow} \sigma^{2}\left|\sigma^{2}(\omega, t] \Rightarrow r \underset{(\infty)}{\nrightarrow} \sigma^{2}\right| I_{\sigma^{2}}(t), \\
\sigma^{2} \underset{1}{\nrightarrow} r\left|r(\omega, t] \Rightarrow \sigma^{2} \underset{(\infty)}{\nrightarrow} r\right| I_{r}(t),
\end{gathered}
$$

where $I_{\sigma^{2}}(t)=I_{0}+\sigma^{2}(\omega, t]$ and $I_{r}(t)=I_{0}+r(\omega, t]$. A measure of causality from $r$ to $\sigma^{2}$ at horizon $h$, denoted $C\left(r \underset{h}{\longrightarrow} \sigma^{2}\right)$, is given by following function [see Dufour and Taamouti (2010)]:

$$
C\left(r \underset{h}{\longrightarrow} \sigma^{2}\right)=\ln \left[\frac{\operatorname{Var}\left[u\left[\sigma_{t+h}^{2} \mid I_{\sigma^{2} z}(t)\right]\right]}{\operatorname{Var}\left[u\left[\sigma_{t+h}^{2} \mid I_{r \sigma^{2} z}(t)\right]\right]}\right] .
$$

Similarly, a measure of causality from $\sigma^{2}$ to $r$ at horizon $h$, denoted $C\left(\sigma^{2} \underset{h}{\longrightarrow} r\right)$, is given by:

$$
C\left(\sigma^{2} \underset{h}{\longrightarrow} r\right)=\ln \left[\frac{\operatorname{Var}\left[u\left[r_{t+h} \mid I_{r z}(t)\right]\right]}{\operatorname{Var}\left[u\left[\left.r_{t+h}\right|_{r \sigma^{2} z}(t)\right]\right]}\right] .
$$

For example, $C\left(r \underset{h}{\longrightarrow} \sigma^{2}\right)$ measures the causal effect from $r$ to $\sigma^{2}$ at horizon $h$ given the past of $\sigma^{2}$ and $z$. In terms of predictability, it measures the information given by the past of $r$ that can improve the forecast of $\sigma_{t+h}^{2}$. Since $\operatorname{Var}\left[u\left[\sigma_{t+h}^{2} \mid I_{\sigma^{2} z}(t)\right]\right] \geq \operatorname{Var}\left[u\left[\sigma_{t+h}^{2} \mid I_{r \sigma^{2} z}(t)\right]\right]$, the function $C\left(r \underset{h}{\longrightarrow} \sigma^{2}\right)$ is nonnegative. Furthermore, it is zero when there is no causality at horizon $h$. However, as soon as there is causality at horizon 1 , causality measures at different horizons may considerably differ.

In Dufour and Taamouti (2010), a measure of instantaneous causality between $r$ and $\sigma^{2}$ at horizon $h$ is also proposed. It is given by the function

$$
C\left(r \underset{h}{\leftrightarrow} \sigma^{2}\right)=\ln \left[\frac{\operatorname{Var}\left[u\left[\left.r_{t+h}\right|_{r \sigma^{2} z}(t)\right]\right] \operatorname{Var}\left[u\left[\sigma_{t+h}^{2} \mid I_{r \sigma^{2} z}(t)\right]\right]}{\operatorname{det}\left(\Sigma\left[r_{t+h}, \sigma_{t+h}^{2} \mid I_{r \sigma^{2} z}(t)\right]\right)}\right]
$$

where $\operatorname{det}\left(\Sigma\left[r_{t+h}, \sigma_{t+h}^{2} \mid I_{r \sigma^{2} z}(t)\right]\right)$ represents the determinant of the variance-covariance matrix $\Sigma\left[r_{t+h}, \sigma_{t+h}^{2} \mid I_{r \sigma^{2} z}(t)\right]$ of the forecast error of the joint process $\left(r, \sigma^{2}\right)^{\prime}$ at horizon $h$ given the information set $I_{r \sigma^{2} z}(t)$. Note that $\sigma^{2}$ may be replaced by $\ln \left(\sigma^{2}\right)$. Since the logarithmic transformation is nonlinear, this may modify the value of the causality measure.

In what follows, we apply the above measures to study causality at different horizons from returns to volatility (hereafter leverage effect), from volatility to returns (hereafter volatility feedback effect), and the instantaneous causality and dependence between returns and volatility. In Section 3, we study these effects by considering a limited information set which only contains the past of returns and realized volatility. In Section 4, we include lagged implied volatility in the information set. 


\section{Measuring leverage and volatility feedback effects in a VAR model}

In this section, we study the relationship between the return $r_{t}$ and its volatility $\sigma_{t}^{2}$. The objective is to measure and compare the strength of dynamic leverage and volatility feedback effects in high-frequency equity data. These effects are quantified within the context of a VAR model and by using short and long run causality measures proposed by Dufour and Taamouti (2010). Since the volatility asymmetry may be the result of causality from returns to volatility [leverage effect], from volatility to returns [volatility feedback effect], instantaneous causality, all of these causal effects, or some of them. We wish to measure and compare these effects in order to determine the most important ones.

We suppose that the joint process of returns and logarithmic volatility, $\left(r_{t+1}, \ln \left(\sigma_{t+1}^{2}\right)\right)^{\prime}$ follows an autoregressive linear model

$$
\left(\begin{array}{c}
r_{t+1} \\
\ln \left(\sigma_{t+1}^{2}\right)
\end{array}\right)=\left(\begin{array}{c}
\mu_{r} \\
\mu_{\sigma}
\end{array}\right)+\sum_{j=1}^{p}\left[\begin{array}{ll}
\Phi_{11 j} & \Phi_{12 j} \\
\Phi_{21 j} & \Phi_{22 j}
\end{array}\right]\left(\begin{array}{c}
r_{t+1-j} \\
\ln \left(\sigma_{t+1-j}^{2}\right)
\end{array}\right)+\left(\begin{array}{c}
u_{t+1}^{r} \\
u_{t+1}^{\sigma}
\end{array}\right)
$$

with $\mathrm{E}\left[u_{t}\right]=0$ and $\operatorname{Var}\left[u_{t}\right]=\Sigma_{u}$, where $u_{t}=\left(u_{t}^{r}, u_{t}^{\sigma}\right)^{\prime}$. In the empirical application $\sigma_{t+1}^{2}$ will be replaced by the realized volatility $R V_{t+1}$ or the bipower variation $B V_{t+1}$. The disturbance $u_{t+1}^{r}$ is the onestep-ahead error when $r_{t+1}$ is forecast from its own past and the past of $\ln \left(\sigma_{t+1}^{2}\right)$, and similarly $u_{t+1}^{\sigma}$ is the one-step-ahead error when $\ln \left(\sigma_{t+1}^{2}\right)$ is forecast from its own past and the past of $r_{t+1}$. We suppose that these disturbances are each serially uncorrelated, but may be correlated with each other contemporaneously and at various leads and lags. Since $u_{t+1}^{r}$ is uncorrelated with $I_{r \sigma^{2}}(t)$, the equation for $r_{t+1}$ represents the linear projection of $r_{t+1}$ on $I_{r \sigma^{2}}(t)$. Likewise, the equation for $\ln \left(\sigma_{t+1}^{2}\right)$ represents the linear projection of $\ln \left(\sigma_{t+1}^{2}\right)$ on $I_{r \sigma^{2}}(t)$.

Equation (3.1) models the first two conditional moments of the asset returns. We represent conditional volatility as an exponential function process to guarantee that it is positive. The first equation in (3.1) describes the dynamics of the return as

$$
r_{t+1}=\mu_{r}+\sum_{j=1}^{p} \Phi_{11 j} r_{t+1-j}+\sum_{j=1}^{p} \Phi_{12 j} \ln \left(\sigma_{t+1-j}^{2}\right)+u_{t+1}^{r} .
$$

This equation allows to capture the temporary component of Fama and French (1988) permanent and temporary components model, in which stock prices are governed by a random walk and a stationary autoregressive process, respectively. For $\Phi_{12 j}=0$, this model of the temporary component is the same as that of Lamoureux and Lastrapes (1993); see also Brandt and Kang (2004), and Whitelaw (1994). The second equation in (3.1) describes the volatility dynamics as

$$
\ln \left(\sigma_{t+1}^{2}\right)=\mu_{\sigma}+\sum_{j=1}^{p} \Phi_{21 j} r_{t+1-j}+\sum_{j=1}^{p} \Phi_{22 j} \ln \left(\sigma_{t+1-j}^{2}\right)+u_{t+1}^{\sigma},
$$

which is a stochastic volatility model. For $\Phi_{21 j}=0$, equation (3.2) can be viewed as the stochastic volatility model estimated by Wiggins (1987), Andersen and Sørensen (1996), and many others. However, in this 
paper, we consider that $\sigma_{t+1}^{2}$ is not a latent variable and it can be approximated by realized or bipower variations from high-frequency data. We also note that the conditional mean equation includes the volatilityin-mean model used by French et al. (1987) and Glosten et al. (1993) to explore the contemporaneous relationship between the conditional mean and volatility [see Brandt and Kang (2004)]. To illustrate the connection to the volatility-in-mean model, we premultiply the system in (3.1) by the matrix

$$
P=\left[\begin{array}{cc}
1 & -\frac{\operatorname{Cov}\left(r_{t+1}, \ln \left(\sigma_{t+1}^{2}\right)\right)}{\operatorname{Var}\left[\ln \left(\sigma_{t+1}^{2}\right) \mid I_{r \sigma^{2}}(t)\right]} \\
-\frac{\operatorname{Cov}\left(r_{t+1}, \ln \left(\sigma_{t+1}^{2}\right)\right)}{\operatorname{Var}\left[r_{t+1} \mid I_{r \sigma^{2}}(t)\right]} & 1
\end{array}\right] .
$$

Then, the first equation of $r_{t+1}$ is a linear function of the elements of $r(\omega, t], \sigma^{2}(\omega, t+1]$, and the disturbance $u_{t+1}^{r}-\frac{\operatorname{Cov}\left(r_{t+1}, \ln \left(\sigma_{t+1}^{2}\right)\right)}{\operatorname{Var}\left[\ln \left(\sigma_{t+1}^{2}\right) \mid I_{r \sigma^{2}}(t)\right]} u_{t+1}^{\sigma}$. Since this disturbance is uncorrelated with $u_{t+1}^{\sigma}$, it is uncorrelated with $\ln \left(\sigma_{t+1}^{2}\right)$ as well as with $r(\omega, t]$ and $\sigma^{2}(\omega, t+1]$. Hence the linear projection of $r_{t+1}$ on $r(\omega, t]$ and $\sigma^{2}(\omega, t+$ $1]$ is provided by the first equation of the new system:

$$
r_{t+1}=\nu_{r}+\sum_{j=1}^{p} \phi_{11 j} r_{t+1-j}+\sum_{j=0}^{p} \phi_{12 j} \ln \left(\sigma_{t+1-j}^{2}\right)+\tilde{u}_{t+1}^{r} .
$$

The new parameters $\nu_{r}, \phi_{11 j}$, and $\phi_{12 j}$, for $j=0,1, \ldots, p$, are functions of parameters in the vector $\mu$ and matrix $\Phi_{j}$, for $j=1, \ldots, p$. Equation (3.3) is a generalized version of the usual volatility-in-mean model, in which the conditional mean depends contemporaneously on the conditional volatility. Similarly, the existence of the linear projection of $\ln \left(\sigma_{t+1}^{2}\right)$ on $r(\omega, t+1]$ and $\sigma^{2}(\omega, t]$,

$$
\ln \left(\sigma_{t+1}^{2}\right)=\nu_{\sigma}+\sum_{j=0}^{p} \phi_{21 j} r_{t+1-j}+\sum_{j=1}^{p} \phi_{22 j} \ln \left(\sigma_{t+1-j}^{2}\right)+\tilde{u}_{t+1}^{\sigma}
$$

follows from the second equation of the new system. The new parameters $\nu_{\sigma}, \phi_{21 j}$, and $\phi_{22 j}$, for $j=$ $1, \ldots, p$, are functions of parameters in the vector $\mu$ and matrices $\Phi_{j}, j=1, \ldots, p$. The volatility model given by equation (3.4) captures the persistence of volatility through the coefficients $\phi_{22 j}$. In addition, it incorporates the effects of the mean on volatility, both at the contemporaneous and intertemporal levels through the coefficients $\phi_{21 j}$, for $j=0,1, \ldots, p$.

Based on system (3.1), the forecast error of $\left(r_{t+h}, \ln \left(\sigma_{t+h}^{2}\right)\right)^{\prime}$ is given by:

$$
e\left[\left(r_{t+h}, \ln \left(\sigma_{t+h}^{2}\right)\right)^{\prime}\right]=\sum_{i=0}^{h-1} \psi_{i} u_{t+h-i}
$$

where the coefficients $\psi_{i}$ are the impulse response coefficients of the $M A(\infty)$ representation of (3.1). The covariance matrix of the forecast error (3.5) is given by

$$
\operatorname{Var}\left[e\left[\left(r_{t+h}, \ln \left(\sigma_{t+h}^{2}\right)\right)^{\prime}\right]\right]=\sum_{i=0}^{h-1} \psi_{i} \Sigma_{u} \psi_{i}^{\prime}
$$


We also consider the following restricted model:

$$
\left(\begin{array}{c}
r_{t+1} \\
\ln \left(\sigma_{t+1}^{2}\right)
\end{array}\right)=\left(\begin{array}{c}
\bar{\mu}_{r} \\
\bar{\mu}_{\sigma}
\end{array}\right)+\sum_{j=1}^{\bar{p}}\left[\begin{array}{ll}
\bar{\Phi}_{11 j} & 0 \\
0 & \bar{\Phi}_{22 j}
\end{array}\right]\left(\begin{array}{c}
r_{t+1-j} \\
\ln \left(\sigma_{t+1-j}^{2}\right)
\end{array}\right)+\left(\begin{array}{l}
\bar{u}_{t+1}^{r} \\
\bar{u}_{t+1}^{\sigma}
\end{array}\right)\left(\begin{array}{c}
\bar{u}_{t+1}^{r} \\
\bar{u}_{t+1}^{\sigma}
\end{array}\right)
$$

with $\mathrm{E}\left[\bar{u}_{t}\right]=0$ and $\operatorname{Var}\left[\bar{u}_{t}\right]=\bar{\Sigma}_{u}$, where $\bar{u}_{t}=\left(\bar{u}_{t}^{r}, \bar{u}_{t}^{\sigma}\right)^{\prime}$. Zero values in the autoregressive matrix coefficients mean that there is noncausality at horizon 1 from returns to volatility and from volatility to returns. As mentioned in subsection 2.2, in a bivariate system, noncausality at horizon one implies noncausality at any horizon $h$ strictly higher than one. This means that the absence of leverage effect at horizon one (respectively the absence of volatility feedback effect at horizon one) which corresponds to $\bar{\Phi}_{21 j}=0$, for $j=1, \ldots, \bar{p}$, (respectively $\bar{\Phi}_{12 j}=0$, for $j=1, \ldots, \bar{p}$, ) is equivalent to the absence of leverage effect (respectively volatility feedback effect) at any horizon $h \geq 1$.

To compare the forecast error variance of model (3.1) with that of model (3.7), we assume that $p=\bar{p}$. Based on the restricted model (3.7), the covariance matrix of the forecast error of $\left(r_{t+h}, \ln \left(\sigma_{t+h}^{2}\right)\right)^{\prime}$ is given by:

$$
\overline{\operatorname{Var}}\left[\bar{e}\left[\left(r_{t+h}, \ln \left(\sigma_{t+h}^{2}\right)\right)^{\prime}\right]\right]=\sum_{i=0}^{h-1} \bar{\psi}_{i} \bar{\Sigma}_{\bar{u}} \bar{\psi}_{i}^{\prime}
$$

where the coefficients $\bar{\psi}_{i}$, for $i=0, \ldots, h-1$, represent the impulse response coefficients of the $M A(\infty)$ representation of model (3.7). From the covariance matrices (3.6) and (3.8), we define the following measures of leverage and volatility feedback effects at any horizon $h$, where $h \geq 1$,

$$
\begin{aligned}
& C\left(r \underset{h}{\longrightarrow} \ln \left(\sigma^{2}\right)\right)=\ln \left[\frac{\sum_{i=0}^{h-1} e_{2}^{\prime}\left(\bar{\psi}_{i} \bar{\Sigma}_{\bar{u}} \bar{\psi}_{i}^{\prime}\right) e_{2}}{\sum_{i=0}^{h-1} e_{2}^{\prime}\left(\psi_{i} \Sigma_{u} \psi_{i}^{\prime}\right) e_{2}}\right], e_{2}=(0,1)^{\prime}, \\
& C\left(\ln \left(\sigma^{2}\right) \underset{h}{\longrightarrow} r\right)=\ln \left[\frac{\sum_{i=0}^{h-1} e_{1}^{\prime}\left(\bar{\psi}_{i} \bar{\Sigma}_{\bar{u}} \bar{\psi}_{i}^{\prime}\right) e_{1}}{\sum_{i=0}^{h-1} e_{1}^{\prime}\left(\psi_{i} \Sigma_{u} \psi_{i}^{\prime}\right) e_{1}}\right], e_{1}=(1,0)^{\prime} .
\end{aligned}
$$

The parametric measure of instantaneous causality at horizon $h$, where $h \geq 1$, is given by the following function

$$
C\left(r \stackrel{\leftrightarrow}{h} \ln \left(\sigma^{2}\right)\right)=\ln \left[\frac{\left(\sum_{i=0}^{h-1} e_{2}^{\prime}\left(\psi_{i} \Sigma_{u} \psi_{i}^{\prime}\right) e_{2}\right)\left(\sum_{i=0}^{h-1} e_{1}^{\prime}\left(\psi_{i} \Sigma_{u} \psi_{i}^{\prime}\right) e_{1}\right)}{\operatorname{det}\left(\sum_{i=0}^{h-1} \psi_{i} \Sigma_{u} \psi_{i}^{\prime}\right)}\right]
$$

\section{Implied volatility as an auxiliary variable}

An important feature of causality is the information set considered to forecast the variables of interest. Until now, we have included only the past of returns and realized volatility. Since the volatility feedback effect rests on anticipating future movements in volatility it is natural to include option-based implied volatility, an all-important measure of market expectations of future volatility. Formally, we "add" the past of implied volatility to the information set $I_{r \sigma^{2}}(t)$ considered in the previous section. The new information set is given now by $I_{r \sigma^{2} z}(t)$, where $z$ is an auxiliary variable represented by implied volatility.

To take implicit volatility into account, we consider call options written on S\&P 500 index futures 
contracts. The data come from the OptionMetrics data set on option prices, dating back to January 1996. Given observations on the option price $C$ and the remaining variables $S, K, \tau$, and $r$, an estimate of the implied volatility $I V$ can be obtained by solving the nonlinear equation $C=C\left(S, K, \tau, r, I V^{1 / 2}\right)$ for $I V^{1 / 2}$, where $C(\cdot)$ refers to the Black-Scholes formula. Each day, we extract the implied volatility corresponding to the option that is closest to the money. This selection criterion ensures that the option will be liquid and therefore aggregates the opinion of many investors about future volatility. This appears more important than keeping a fixed maturity. This choice is often made in the empirical literature on option pricing [see for example Pan (2002)]. Summary statistics for the daily implied volatility $\left(I V^{1 / 2}\right)$, squared implied volatility $(I V)$ and logarithm of squared implied volatility $(\ln (I V))$ are reported in Table 3 .

Therefore, we consider a trivariate autoregressive model including implied volatility, in addition to the realized volatility (bipower variation) and returns: ${ }^{9}$

$$
\left[\begin{array}{c}
r_{t+1} \\
R V_{t+1}^{*} \\
I V_{t+1}^{*}
\end{array}\right]=\left[\begin{array}{c}
\mu_{r} \\
\mu_{R V} \\
\mu_{I V}
\end{array}\right]+\sum_{j=1}^{p}\left[\begin{array}{ccc}
\Phi_{11 j} & \Phi_{12 j} & \Phi_{13 j} \\
\Phi_{21 j} & \Phi_{22 j} & \Phi_{23 j} \\
\Phi_{31 j} & \Phi_{32 j} & \Phi_{33 j}
\end{array}\right]\left[\begin{array}{c}
r_{t+1-j} \\
R V_{t+1-j}^{*} \\
I V_{t+1-j}^{*}
\end{array}\right]+\left[\begin{array}{c}
u_{t+1}^{r} \\
u_{t+1}^{R V} \\
u_{t+1}^{I V}
\end{array}\right]
$$

where $R V_{t}^{*}=\ln \left(R V_{t}\right)$ and $I V_{t}^{*}=\ln \left(I V_{t}\right)$. The first equation of the above system

$$
r_{t+1}=\mu_{r}+\sum_{j=1}^{p} \Phi_{11 j} r_{t+1-j}+\sum_{j=1}^{p} \Phi_{12 j} R V_{t+1-j}^{*}+\sum_{j=1}^{p} \Phi_{13 j} I V_{t+1-j}^{*}+u_{t+1}^{r}
$$

describes the dynamics of the return, while the second equation

$$
R V_{t+1}^{*}=\mu_{R V}+\sum_{j=1}^{p} \Phi_{21 j} r_{t+1-j}+\sum_{j=1}^{p} \Phi_{22 j} R V_{t+1-j}^{*}+\sum_{j=1}^{p} \Phi_{23 j} I V_{t+1-j}^{*}+u_{t+1}^{R V}
$$

describes the volatility dynamics. It is well known that implied volatility can be used to predict whether a market is likely to move higher or lower and help to predict future volatility [see Day and Lewis (1992), Canina and Figlewski (1993), Lamoureux and Lastrapes (1993), Poteshman (2000), Blair et al. (2001), and Busch et al. (2010)]. The forward-looking nature of the implied volatility measure makes it an ideal additional variable to capture a potential volatility feedback mechanism. Apart from using $I V$ without any constraint in (4.2) and (4.3), we will also look at more restricted combinations dictated by financial considerations. Indeed, the difference between $I V$ and $R V$ provides an estimate of the risk premium attributable to the variance risk factor.

\section{Causality measures for $S \& P 500$ futures}

In this section, we first describe the data used to measure causality in the VAR models of the previous sections. Then we explain how to estimate confidence intervals of causality measures for leverage and volatility feedback effects. Finally, we discuss our findings.

\footnotetext{
${ }^{9}$ Further, we consider an autoregressive model where we add jumps and our results do not change.
} 


\subsection{Data description}

Our data consists of high-frequency tick-by-tick transaction prices on S\&P 500 Index futures contracts traded on the Chicago Mercantile Exchange, over the period January 1988 to December 2005 for a total of 4494 trading days. We eliminated a few days where trading was thin and the market was open for a shortened session. Due to the unusually high volatility at the opening, we also omit the first five minutes of each trading day [see Bollerslev et al. (2006)]. For reasons associated with microstructure effects we follow Bollerslev et al. (2006) and the literature in general and aggregate returns over five-minute intervals. We calculate the continuously compounded returns over each five-minute interval by taking the difference between the logarithm of the two tick prices immediately preceding each five-minute mark to obtain a total of 77 observations per day [see Müller, Dacorogna, Davé, Olsen, Pictet and Von Weizsäcker (1997) and Bollerslev et al. (2006) for more details]. We also construct hourly and daily returns by summing 11 and 77 successive five-minute returns, respectively.

Summary statistics for the five-minute, hourly, and daily returns and the associated volatilities are reported in tables $1-2$. From these, we see that the unconditional distributions of the returns exhibit high kurtosis and negative skewness. The sample kurtosis is much greater than the Gaussian value of three for all series. The negative skewness remains moderate, especially for the five-minute and daily returns. Similarly, the unconditional distributions of realized and bipower volatility measures are highly skewed and leptokurtic. However, on applying a logarithmic transformation, both measures appear approximately normal [see Andersen, Bollerslev, Diebold and Ebens (2001)]. The descriptive statistics for the relative jump measure, $J_{t+1}$, clearly indicate a positively skewed and leptokurtic distribution.

It is also of interest to assess whether the realized and bipower volatility measures differ significantly. To test this, recall that

$$
\lim _{\Delta \rightarrow 0}\left(R V_{t+1}\right)=\int_{t}^{t+1} \sigma_{s}^{2} d s+\sum_{0<s \leq t} \kappa_{s}^{2}
$$

where $\int_{t}^{t+1} \sigma_{s}^{2} d s$ is the integrated volatility and $\sum_{0<s \leq t} \kappa_{s}^{2}$ represents the contribution of jumps to total price variation. In the absence of jumps, the second term on the right-hand-side disappears, and the quadratic variation is simply equal to the integrated volatility: or asymptotically $(\Delta \rightarrow 0)$ the realized variance is equal to the bipower variance. Many statistics have been proposed to test for the presence of jumps in financial data; see for example Barndorff-Nielsen and Shephard (2002b), Andersen, Bollerslev and Diebold (2003), Huang and Tauchen (2005). In this paper, we test for the presence of jumps in our data by considering the following test statistics:

$$
\begin{gathered}
z_{Q P, l, t}=\frac{R V_{t+1}-B V_{t+1}}{\sqrt{\left(\left(\frac{\pi}{2}\right)^{2}+\pi-5\right) \Delta Q P_{t+1}}}, \\
z_{Q P, t}=\frac{\ln \left(R V_{t+1}\right)-\ln \left(B V_{t+1}\right)}{\sqrt{\left(\left(\frac{\pi}{2}\right)^{2}+\pi-5\right) \Delta \frac{Q P_{t+1}}{B V_{t+1}^{2}}}}, \\
z_{Q P, l m, t}=\frac{\ln \left(R V_{t+1}\right)-\ln \left(B V_{t+1}\right)}{\sqrt{\left(\left(\frac{\pi}{2}\right)^{2}+\pi-5\right) \Delta \max \left(1, \frac{Q P_{t+1}}{B V_{t+1}^{2}}\right)}},
\end{gathered}
$$


where $Q P_{t+1}$ is the realized Quad-Power Quarticity [Barndorff-Nielsen and Shephard (2002a)], with

$$
Q P_{t+1}=h \mu_{1}^{-4} \sum_{j=4}^{h}\left|r_{(t+j . \Delta, \Delta)}\left\|r_{(t+(j-1) . \Delta, \Delta)}\right\| r_{(t+(j-2) . \Delta, \Delta)} \| r_{(t+(j-3) . \Delta, \Delta)}\right|
$$

and $\mu_{1}=\sqrt{\frac{2}{\pi}}$. Under the assumption of no jumps and for each time $t$, the statistics $z_{Q P, l, t}, z_{Q P, t}$, and $z_{Q P, l m, t}$ follow a Normal distribution $\mathcal{N}(0,1)$ as $\Delta \rightarrow 0$. The results of testing for jumps in our data are plotted in Figure 1. These graphs represent the quantile to quantile plots (hereafter QQ plot) of the relative measure of jumps given by equation (2.5) and the QQ Plots of the other statistics; $z_{Q P, l, t}, z_{Q P, t}$, and $z_{Q P, l m, t}$. When there are no jumps, we expect that the cross line and the dotted line in Figure 1 will coincide. However, as this figure shows, the two lines are clearly distinct, indicating the presence of jumps in our data. Therefore, we will present our results for both realized volatility and bipower variation.

\subsection{Causality measures}

We examine several empirical issues regarding the relationship between volatility and returns. Before highfrequency data became available and the concept of realized volatility took root, such issues could only be addressed through volatility models. Recently, Bollerslev et al. (2006) looked at these relationships using high-frequency data and realized volatility measures. As they emphasize, the fundamental difference between the leverage and the volatility feedback explanations lies in the direction of causality. The leverage effect explains why a low return causes higher subsequent volatility, while the volatility feedback effect captures how an increase in volatility may cause a negative return. However, they studied only correlations between returns and volatility at various leads and lags, not causality relationships.

Here, we apply short-run and long-run causality measures to quantify the strength of the relationships between return and volatility at various horizons. We use OLS to estimate the VAR models described above and the Akaike information criterion to specify their orders. ${ }^{10}$ To obtain consistent estimates of the causality measures, we simply replace the unknown parameters by their estimates. We calculate causality measures for various horizons $h=1, \ldots, 20$. A higher value for a causality measure indicates a stronger causality. We also compute the corresponding nominal $95 \%$ bootstrap percentile confidence intervals using two different methods: the first one is based on the procedure described in Dufour and Taamouti (2010, p. 52) and the second one corresponds to the fixed-design wild bootstrap described in Gonçalves and Kilian (2004, Section 3.2). Further, the new confidence intervals were built after accounting for a possible bias in the autoregressive coefficients. ${ }^{11}$ As mentioned by Inoue and Kilian (2002), for bounded measures, as in our case, the bootstrap approach is more reliable than the delta-method. One reason is because the deltamethod interval is not range respecting and may produce confidence intervals that are invalid. In contrast, the bootstrap percentile interval preserves by construction these constraints [see Inoue and Kilian (2002,

\footnotetext{
${ }^{10}$ Using Akaike's criterion we find that the appropriate value of the order of the unconstrained autoregressive model is equal to 10. Since using the same criterion the value of the order of the constrained model is smaller than 10 , we take $p=\bar{p}=10$ [see Section 3].

${ }^{11}$ More details on bias-correction in causality measures see the end of Section 8 in Dufour and Taamouti (2010).
} 
pages 315-318) and Efron and Tibshirani (1993)]. Further, the percentile interval allows avoiding using the variance-covariance matrix of the estimators that can depend on the homoskedasticity assumption. More details on the consistency and statistical justification of the above two procedures are available in Dufour and Taamouti (2010) and Gonçalves and Kilian (2004).

The concept of Granger causality requires an information set and is analyzed in the framework of a model between the variables of interest. Both the strength of this causal link and its statistical significance are important. A major complication in detecting causality is aggregation. Low frequency data may mask the true causal relationship between variables. High-frequency data thus offer an opportunity to analyze causal effects. In particular, we can distinguish with an exceptionally high resolution between immediate and lagged effects. Further, even if our interest focuses on relationships at the daily frequency, using higherfrequency data to construct daily returns and volatilities can provide better estimates than using daily returns (as done in previous studies). Besides, since measured realized volatility can be viewed as an approximation to the "true" unobservable volatility, we consider both raw realized volatility and the bipower variation (which provides a way to filter out possible jumps in the data); see Barndorff-Nielsen and Shephard (2004).

With five-minute intervals we could estimate the VAR model at this frequency. However, if we wish to allow for enough time for the effects to develop, we need a large number of lags in the VAR model and sacrifice efficiency in the estimation. This problem arises in many studies of volatility forecasting. Researchers have use several schemes to group five-minute intervals, in particular the HAR-RV or the MIDAS schemes. ${ }^{12}$ We decided to look both at hourly and daily frequencies.

In this section and next ones, our empirical results will be presented mainly through graphs. Each figure reports the causality measure as a function of the horizon. To preserve space and reduce the number of graphs, we exclude almost all the graphs with confidence intervals and we focus on the main figures where different effects are compared across horizons. However, in the paper we discuss the results of statistical significance of the effects. ${ }^{13}$

The main results that correspond to the present section are summarized and compared in figures 2 5. Results based on bivariate models indicate the following (see Figure 2 and Table 4). When returns are aggregated to the hourly frequency, we find that the leverage effect is statistically significant for the first four hours, while the volatility feedback effect is negligible at all horizons. Using daily observations, derived from high-frequency data, we find a strong leverage effect for the first three days, while the volatility feedback effect appears to be negligible at all horizons. The results based on realized volatility $(R V)$ and bipower variation $(B V)$ are essentially the same. Overall, these results show that the leverage effect is more important than the volatility feedback effect (Figure 2).

If the feedback effect from volatility to returns is almost-non-existent, we find that the instantaneous causality between these variables exists and remains economically and statistically important for several

\footnotetext{
${ }^{12}$ The HAR-RV scheme, in which the realized volatility is parameterized as a linear function of the lagged realized volatilities over different horizons has been proposed by Müller et al. (1997) and Corsi (2009). The MIDAS scheme, based on the idea of distributed lags, has been analyzed and estimated by Ghysels, Santa-Clara and Valkanov (2002).

${ }^{13}$ Detailed results, including confidence bands on the causality measures, are presented in a separate companion document [Dufour, Garcia and Taamouti (2010) available from one the authors' homepage (www.jeanmariedufour.com)].
} 
days. This means that volatility has a contemporaneous effect on returns, and similarly returns have a contemporaneous effect on volatility. These results are confirmed with both realized and bipower variations. Furthermore, dependence between volatility and returns is also economically and statistically important for several days.

Let us now consider a trivariate autoregressive model including implied volatility in addition to realized volatility (bipower variation) and returns, as suggested in Section 4 (figures 3 - 5). First, we find that implied volatility $(I V)$ helps to predict future realized volatility for several days ahead (Figure 3). Many other papers like Day and Lewis (1992), Canina and Figlewski (1993), Lamoureux and Lastrapes (1993) among others, also find that implied volatility can be used to predict future volatility. However, the difference is that in the present paper we look at $h$-step ahead forecast, for $h \geq 1$, whereas the previous papers only focus on one step-ahaed forecast. Note that Bollerslev et al. (2006) do not consider implied volatility in their analysis.

Second, there is an important increase in the volatility feedback effect when implied volatility is taken into account (Figure 4). In particular, it is statistically significant during the first four days. The volatility feedback effect relies first on the volatility clustering phenomena which means that return shocks, positive or negative, increases both current and future volatility. The second basic explanation of this hypothesis is that there is a positive intertemporal relationship between conditional volatility and expected returns. Thus, given the anticipative role of implied volatility and the link between the volatility feedback effect and future volatility, implied volatility reinforces and increases the impact of volatility on returns. ${ }^{14}$ Figure 4 also compares volatility feedback effects with and without implied volatility as an auxiliary variable. We see that the difference between $I V$ and $R V$ has a stronger impact on returns than realized volatility alone in the presence of implied volatility. Further, different transformations of volatility (logarithmic of volatility and standard deviation) are considered: the volatility feedback effect is strongest when the standard deviation is used to measure volatility.

Finally, we look at the leverage effects with and without implied volatility as an auxiliary variable (Figure 5). We see that there is almost no change in the leverage effect when we take into account implied volatility. On comparing the leverage and volatility feedback effects with and without implied volatility, we see that the difference, in terms of causality measure, between leverage and volatility feedback effects decreases when implied volatility is included in the information set. In other words, taking into account implied volatility allows to identify a volatility feedback effect without affecting the leverage effect. This may reflect the fact that investors use several markets to carry out their financial strategies, and information is disseminated across several markets. Since the identification of a causal relationship depends crucially on the specification of the information set, including implied volatility appears essential to demonstrate a volatility feedback effect.

\footnotetext{
${ }^{14}$ Since option prices reflect market participants' expectations of future movements of the underlying asset, the volatility implied from option prices should be an efficient forecast of future volatility, which potentially explains a better identification of the volatility feedback effect.
} 


\section{Dynamic impact of positive and negative news on volatility}

In the previous sections, we did not account for the fact that return news may differently affect volatility depending on whether they are good or bad. We will now propose a method to sort out the differential effects of good and bad news, along with a simulation study showing that our approach can indeed detect asymmetric responses of volatility to return shocks.

\subsection{Theory}

Several volatility models capture this asymmetry and are explored in Engle and $\mathrm{Ng}$ (1993). To study the effect of current return shocks on future expected volatility, Engle and $\mathrm{Ng}$ (1993) introduced the News Impact Function (hereafter $N I F$ ). The basic idea of this function is to consider the effect of the return shock at time $t$ on volatility at time $t+1$ in isolation while conditioning on information available at time $t$ and earlier. Recently, Chen and Ghysels (2010) have extended the concept of news impact curves to the high-frequency data setting. Instead of taking a single horizon fixed parametric framework they adopt a flexible multi-horizon semi-parametric modeling [see also Linton and Mammen (2005)].

In what follows we extend our previous VAR model to capture the dynamic impact of bad news (negative innovations in returns) and good news (positive innovations in returns) on volatility. We quantify and compare the strength of these effects in order to determine the most important ones. To analyze the impact of news on volatility, we consider the following model:

$$
\ln \left(\sigma_{t+1}^{2}\right)=\mu_{\sigma}+\sum_{j=1}^{p} \varphi_{j}^{\sigma} \ln \left(\sigma_{t+1-j}^{2}\right)+\sum_{j=1}^{p} \varphi_{j}^{-} e r_{t+1-j}^{-}+\sum_{j=1}^{p} \varphi_{j}^{+} e r_{t+1-j}^{+}+u_{t+1}^{\sigma}
$$

where

$$
e r_{t+1-j}^{-}=\min \left\{e r_{t+1-j}, 0\right\}, e r_{t+1-j}^{+}=\max \left\{e r_{t+1-j}, 0\right\}, e r_{t+1-j}=r_{t+1-j}-\mathrm{E}_{t-j}\left(r_{t+1-j}\right),
$$

$\mathrm{E}\left[u_{t}^{\sigma}\right]=0$ and $\operatorname{Var}\left[u_{t}^{\sigma}\right]=\Sigma_{u^{\sigma}}$. Equation (6.1) represents the linear projection of volatility on its own past and the past of centered negative and positive returns. This regression model allows one to capture the effect of centered negative or positive returns on volatility through the coefficients $\varphi_{j}^{-}$or $\varphi_{j}^{+}$respectively, for $j=1, \ldots, p$. It also allows one to examine the different effects that large and small negative and/or positive information shocks have on volatility. This will provide a check on the results obtained in the literature on GARCH modeling, which has put forward overwhelming evidence on the effect of negative shocks on volatility.

Again, in our empirical applications, $\sigma_{t+1}^{2}$ will be replaced by realized volatility $R V_{t+1}$ or bipower variation $B V_{t+1}$. Furthermore, the conditional mean return is approximated by the following rolling-sample average:

$$
\hat{E}_{t}\left(r_{t+1}\right)=\frac{1}{m} \sum_{j=1}^{m} r_{t+1-j}
$$


where we take an average around $m=15,30,90,120$, and 240 days. ${ }^{15}$ Now, let us consider the following restricted models:

$$
\begin{aligned}
& \ln \left(\sigma_{t+1}^{2}\right)=\theta_{\sigma}+\sum_{i=1}^{\bar{p}} \bar{\varphi}_{i}^{\sigma} \ln \left(\sigma_{t+1-i}^{2}\right)+\sum_{i=1}^{\bar{p}} \bar{\varphi}_{i}^{+} e r_{t+1-j}^{+}+e_{t+1}^{\sigma}, \\
& \ln \left(\sigma_{t+1}^{2}\right)=\bar{\theta}_{\sigma}+\sum_{i=1}^{\dot{p}} \dot{\varphi}_{i}^{\sigma} \ln \left(\sigma_{t+1-i}^{2}\right)+\sum_{i=1}^{\dot{p}} \dot{\varphi}_{i}^{-} e r_{t+1-j}^{-}+v_{t+1}^{\sigma} .
\end{aligned}
$$

Equation (6.2) represents the linear projection of volatility $\ln \left(\sigma_{t+1}^{2}\right)$ on its own past and the past of centred positive returns. Similarly, equation (6.3) represents the linear projection of volatility $\ln \left(\sigma_{t+1}^{2}\right)$ on its own past and the past of centered negative returns. To compare the forecast error variances of model (6.1) with those of models (6.2) and (6.3), we assume that $p=\bar{p}=\dot{p}$.

Thus, a measure of the impact of bad news on volatility at horizon $h$, where $h \geq 1$, is given by the following equation:

$$
C\left(e r^{-} \underset{h}{\rightarrow} \ln \left(\sigma^{2}\right)\right)=\ln \left[\frac{\operatorname{Var}\left[e_{t+h}^{\sigma}\left[\ln \left(\sigma_{t+h}^{2}\right) \mid\left(\sigma^{2}(\omega, t], e r^{+}(\omega, t]\right)\right]\right]}{\operatorname{Var}\left[u_{t+h}^{\sigma}\left[\ln \left(\sigma_{t+h}^{2}\right) \mid J(t)\right]\right]}\right] .
$$

where $e_{t+h}^{\sigma}\left[\ln \left(\sigma_{t+h}^{2}\right) \mid\left(\sigma^{2}(\omega, t], \mathrm{er}^{+}(\omega, t]\right)\right]\left(u_{t+h}^{\sigma}\left[\ln \left(\sigma_{t+h}^{2}\right) \mid J(t)\right]\right)$ is the $h$-step ahead forecast error of $\log$ volatility based on the information set $\sigma^{2}(\omega, t] \cup \mathrm{er}^{+}(\omega, t](J(t))$. Similarly, a measure of the impact of good news on volatility at horizon $h$ is given by:

$$
C\left(e r^{+} \underset{h}{\rightarrow} \ln \left(\sigma^{2}\right)\right)=\ln \left[\frac{\operatorname{Var}\left[v_{t+h}^{\sigma}\left[\ln \left(\sigma_{t+h}^{2}\right) \mid\left(\sigma^{2}(\omega, t], e r^{-}(\omega, t]\right)\right]\right]}{\operatorname{Var}\left[u_{t+h}^{\sigma}\left[\ln \left(\sigma_{t+h}^{2}\right) \mid J(t)\right]\right]}\right]
$$

where $v_{t+h}^{\sigma}\left[\ln \left(\sigma_{t+h}^{2}\right) \mid\left(\sigma^{2}(\omega, t], \mathrm{er}^{-}(\omega, t]\right)\right]$ is the $h$-step ahead forecast error of log volatility based on the information set $\sigma^{2}(\omega, t] \cup r^{-}(\omega, t]$,

$$
\begin{aligned}
& e r^{-}(\omega, t]=\left\{e r_{t-s}^{-}, s \geq 0\right\} \\
& e r^{+}(\omega, t]=\left\{e r_{t-s}^{+}, s \geq 0\right\}
\end{aligned}
$$

and $J(t)$ is the information set obtained by "adding" $\sigma^{2}(\omega, t]$ to $\mathrm{er}^{-}(\omega, t]$ and $\mathrm{er}^{+}(\omega, t]$. We also define a function which allows us to compare the impact of bad and good news on volatility. This function can be defined as follows:

$$
C\left(e r^{-} / e r^{+} \underset{h}{\rightarrow} \ln \left(\sigma^{2}\right)\right)=\ln \left[\frac{\operatorname{Var}\left[e_{t+h}^{\sigma}\left[\ln \left(\sigma_{t+h}^{2}\right) \mid\left(\sigma^{2}(\omega, t], e r^{+}(\omega, t]\right)\right]\right]}{\operatorname{Var}\left[v_{t+h}^{\sigma}\left[\ln \left(\sigma_{t+h}^{2}\right) \mid\left(\sigma^{2}(\omega, t], e r^{-}(\omega, t]\right)\right]\right]}\right] .
$$

When $C\left(e r^{-} / e r^{+} \underset{h}{\rightarrow} \ln \left(\sigma^{2}\right)\right) \geq 0$, this means that bad news have more impact on volatility than good news. Otherwise, good news have more impact on volatility than bad news. Compared to Chen and Ghysels (2010), our approach is also multi-horizon and based on high-frequency data but is more parametric in

\footnotetext{
${ }^{15}$ In our empirical application, we also considered the case of uncentered returns. The results can be found in Dufour et al. (2010).
} 
nature. Before applying these new measures to our S\&P 500 futures market, we conduct a simulation study to verify that the asymmetric reaction of volatility is well captured in various models of the GARCH family that produce or not such an asymmetry.

\subsection{Simulation study on news asymmetry detection}

We will now present an exploratory simulation study on the ability of causality measures to detect asymmetry in the impact of bad and good news on volatility [Pagan and Schwert (1990), Gouriéroux and Monfort (1992), Engle and $\mathrm{Ng}$ (1993)]. To do this, we consider that returns are governed by a process of the form:

$$
r_{t+1}=\sqrt{\sigma_{t}} \varepsilon_{t+1}
$$

where $\varepsilon_{t+1} \sim \mathcal{N}(0,1)$ and $\sigma_{t}$ represents the conditional volatility of return $r_{t+1}$. Since we are only interested in studying the asymmetry in leverage effect, equation (6.4) does not allow for a volatility feedback effect. Second, we assume that $\sigma_{t}$ follows one of the following heteroskedastic models:

1. $\operatorname{GARCH}(1,1)$ model:

$$
\sigma_{t}=\omega+\beta \sigma_{t-1}+\alpha \varepsilon_{t-1}^{2}
$$

2. $\operatorname{EGARCH}(1,1)$ model:

$$
\log \left(\sigma_{t}\right)=\omega+\beta \log \left(\sigma_{t-1}\right)+\gamma \frac{\varepsilon_{t-1}}{\sqrt{\sigma_{t-1}}}+\alpha\left[\frac{\left|\varepsilon_{t-1}\right|}{\sqrt{\sigma_{t-1}}}-\sqrt{2 / \pi}\right] .
$$

GARCH model is, by construction, symmetric. Thus, we expect that the curves of causality measures for bad and good news will be the same. Similarly, because EGARCH model is asymmetric we expect that these curves will be different. The parameter values considered are from Engle and $\mathrm{Ng}$ (1993). ${ }^{16}$

To see whether the asymmetric structures get translated into the causality patterns, we then simulate returns and volatilities according to the above models and we evaluate the causality measures for bad and good news as described in Section 6.1. To abstract from statistical uncertainty, the models are simulated with a large sample size $(T=40000)$.

The results obtained in this way are reported in Figure 6. We see from these that symmetry and asymmetry are well represented by causality measure patterns. For the symmetric GARCH model, bad and good news have the same impact on volatility. In contrast, for the asymmetric EGARCH model, bad and good news exhibit different impact curves. We also considered many other parametric volatility models like $\operatorname{AGARCH}(1,1), \operatorname{VGARCH}(1,1), \mathrm{NL}-\mathrm{GARCH}, \mathrm{GJR}-\mathrm{GARCH}$ and nonlinear asymmetric $\operatorname{GARCH}(1,1)$ [NGARCH(1,1)], and the results correspond to what we were expecting. ${ }^{17}$

It is also interesting to observe for the asymmetric models that bad news have a greater impact on volatility than good news. The magnitude of the volatility response is largest for NGARCH model, followed

\footnotetext{
${ }^{16}$ These parameters are the results of an estimation of different parametric volatility models using the daily returns series of the Japanese TOPIX index from January 1, 1980 to December 31, 1988. For details, see Engle and Ng (1993). We also considered other values based on Engle and Ng (1993). The results are similar to those presented here [see Dufour et al. (2010)].

${ }^{17}$ See Dufour et al. (2010).
} 
by the AGARCH and GJR-GARCH models. The effect is negligible in EGARCH and VGARCH models. The impact of good news on volatility is more noticeable in AGARCH and NGARCH models. Overall, causality measures appear to capture quite well the effects of returns on volatility, both qualitatively and quantitatively.

\section{News effects in S\&P 500 futures market}

We now apply the good news and bad news measures of causality to S\&P 500 futures returns. To carry out our analysis, we consider two alternative measures of news: (1) positive and negative deviations of returns from average past returns, and (2) positive and negative variance risk premia. An important feature of our approach comes from the fact that a specific volatility model need not be estimated, which can be contrasted with previous related studies [see, for example Bekaert and Wu (2000), Engle and Ng (1993), Glosten et al. (1993), Campbell and Hentschel (1992), and Nelson (1991)].

\subsection{Return news}

Our empirical results on return news effect are summarized and compared in Figure 7. Detailed results (with confidence intervals) are presented in tables 5-6. ${ }^{18}$ We find a much stronger impact of bad news on volatility for several days. Statistically, the impact of bad news is significant for the first four days, whereas the impact of good news is negligible at all horizons. So our central finding is that bad news have more impact on volatility than good news at all horizons.

\subsection{Variance risk premium}

Let us now look at the reaction of future returns to the sign of the difference between implied volatility and realized volatility (bipower variation). This difference is a measure of the variance risk premium since the option-implied volatility includes the risk premium that investors associate with expected future volatility [see Bollerslev and Zhou (2005) and Drechsler and Yaron (2010)]. We will therefore assess whether a positive variance risk premium has an impact of similar magnitude on expected returns than a negative variance risk premium. In the case of a positive variance risk premium, we expect an increase in the expected returns (return risk premium), and in the opposite, we expect a decrease in expected returns.

Since implied volatility is a predictor of future volatility, we write:

$$
\begin{gathered}
\ln \left(R V_{t+h}\right)=f\left(\ln \left(I V_{t}\right), \ln \left(I V_{t-1}\right), \ldots\right)+\varepsilon_{t+h}, \quad \forall h \geq 1, \\
\varepsilon_{t+h}=\ln \left(R V_{t+h}\right)-f\left(\ln \left(I V_{t}\right), \ln \left(I V_{t-1}\right), \ldots\right),
\end{gathered}
$$

where $f\left(\ln \left(I V_{t}\right), \ln \left(I V_{t-1}\right), \ldots\right)$ is a function of the past observations on implied volatility. ${ }^{19}$ The term

\footnotetext{
${ }^{18}$ We also computed the causality measures of the impact of bad news on volatility using other estimators of the conditional mean $(\mathrm{m}=90,120,240)$ and uncentered returns. The results are similar to the ones discussed here [see Dufour et al. (2010)].

${ }^{19} f\left(\ln \left(I V_{t}\right), \ln \left(I V_{t-1}\right), \ldots\right)$ represents the optimal forecast, in the sense of minimization of the mean squared error, of $\ln \left(R V_{t+h}\right)$ based on the past observations of implied volatility.
} 
on the right-hand side of equation (7.1) can be viewed as an approximation of volatility shocks or volatility news. To measure empirically the dynamic impact of volatility news on returns, we consider the following model:

$$
r_{t+1}=\mu_{r}+\sum_{j=1}^{p} \varphi_{j}^{r} r_{t+1-j}+\sum_{j=1}^{p} \varphi_{j}^{-} V P_{t+1-j}^{-}+\sum_{j=1}^{p} \varphi_{j}^{+} V P_{t+1-j}^{+}+u_{t+1}^{r}
$$

where $V P_{t+1-j}^{-}=\min \left\{V P_{t+1-j}, 0\right\}, V P_{t+1-j}^{+}=\max \left\{V P_{t+1-j}, 0\right\}$ and

$$
V P_{t+1-j}=\ln \left(I V_{t+1-j}\right)-\ln \left(R V_{t+1-j}\right), \quad j=1, \ldots, p .
$$

Equation (7.2) represents a linear projection of returns on its own past and the past of negative and positive variance risk premia. This regression model allows one to capture the effect of volatility news on returns through the coefficients $\varphi_{j}^{-}$or $\varphi_{j}^{+}$, for $j=1, \ldots, p$. It also allows one to examine different effects that large and small negative and/or positive volatility shocks have on return risk premium. When implied volatility is bigger than realized volatility (bipower variation), we expect an increase in future volatility followed by an increase in the expected returns. In the opposite situation, we expect a decrease in future volatility followed by a decrease in the expected returns.

The empirical results on the impact of volatility news on returns are given in Figure $7 .^{20}$ The latter compares the impacts of negative and positive variance risk premium on returns. We see that a positive variance risk premium has more impact on expected returns than a negative variance risk premium, which means that positive shocks on volatility have more impact on returns than negative shocks. The impact is twice as big on the first day and shrinks to zero after about five days. By looking at the sign of coefficients $\varphi_{j}^{+}$and $\varphi_{j}^{-}$, for $j=1, \ldots, p$, we find that $\varphi_{j}^{+}$are positive, whereas $\varphi_{j}^{-}$are negative, as expected. Consequently, the increase in expected returns tends to be higher than the decrease for a movement in the variance risk premium of the same magnitude but of opposite signs.

\section{Conclusion}

In this paper, we analyze and quantify the relationship between volatility and returns with high-frequency equity returns. Within the framework of a vector autoregressive linear model of returns and realized volatility or bipower variation, we quantify the dynamic leverage and volatility feedback effects by applying short-run and long-run causality measures proposed by Dufour and Taamouti (2010). These causality measures go beyond simple correlation measures used recently by Bollerslev et al. (2006).

Using 5-minute observations on S\&P 500 Index futures contracts, we measure a weak dynamic leverage effect for the first four hours in hourly data and a strong dynamic leverage effect for the first three days in daily data. The volatility feedback effect is found to be negligible at all horizons. Interestingly, when we remeasure the dynamic leverage and volatility feedback effects using implied volatility $(I V)$, we find that a volatility feedback effect appears, while the leverage effect remains almost the same. This can be explained

\footnotetext{
${ }^{20}$ Detailed results (with confidence intervals) are presented in Dufour et al. (2010).
} 
by the power of implied volatility to predict future volatility and by the fact that volatility feedback effect is related to the latter. We also use causality measures to quantify and test statistically the dynamic impact of good and bad news on volatility. First, we assess by simulation the ability of causality measures to detect the differential effect of good and bad news in various parametric volatility models. Then, empirically, we measure a much stronger impact for bad news at several horizons. Statistically, the impact of bad news is significant for the first four days, whereas the impact of good news is negligible at all horizons. We introduce a new concept of news based on volatility. This one is defined by the difference between implied volatility and realized volatility (bipower variation). When implied volatility is bigger than realized volatility (bipower variation) it means that the market is expecting an increase in future volatility with respect to current volatility. Our empirical results show that such an expected increase in volatility has a stronger impact on return risk premium than an expected decrease of a similar magnitude.

\section{References}

Aigner, D. and Zellner, A., eds (1988), Causality, Special Issue of the Journal of Econometrics, Vol. 39 (No. $1 / 2)$.

Andersen, T. G. and Bollerslev, T. (1998), 'Answering the skeptics: Yes, standard volatility models do provide accurate forecasts', International Economic Review 39(4), 885-905.

Andersen, T. G., Bollerslev, T. and Diebold, F. X. (2003), Some like it smooth, and some like it rough: Untangling continuous and jump components in measuring, modeling, and forecasting asset return volatility, Technical report, Northwestern University, Evanston, Illinois.

Andersen, T. G., Bollerslev, T. and Diebold, F. X. (2010), Parametric and non-parametric volatility measurement, in Y. Ait-Sahalia and L. P. Hansen, eds, 'Handbook of Financial Econometrics. Volume 1 Tools and Techniques', Elsevier, Amsterdam, chapter 2, pp. 67-138.

Andersen, T. G., Bollerslev, T., Diebold, F. X. and Ebens, H. (2001), 'The distribution of stock return volatility', Journal of Financial Economics 61(1), 43-76.

Andersen, T. G., Bollerslev, T., Diebold, F. X. and Labys, P. (2001), 'The distribution of realized exchange rate volatility', Journal of the American Statistical Association 96, 42-55.

Andersen, T. G., Bollerslev, T., Diebold, F. X. and Vega, C. (2003), 'Micro effects of macro announcements: Real-time price discovery in foreign exchange', American Economic Review 93, 38-62.

Andersen, T. G. and Sørensen, B. E. (1996), 'GMM estimation of a stochastic volatility model: A Monte Carlo study', Journal of Business and Economic Statistics 14(3), 328-352.

Balduzzi, P., Elton, E. J. and Green, T. (2001), 'Economic news and bond prices: Evidence from the U.S. treasury market', Journal of Financial and Quantitative Analysis 36, 523-544. 
Barndorff-Nielsen, O. E., Graversen, S. E., Jacod, J., Podolskij, M. and Shephard, N. (2005), A central limit theorem for realized power and bipower variations of continuous semimartingales, in Y. Kabanov and R. Liptser, eds, 'From Stochastic Analysis to Mathematical Finance, Festschrift for Albert Shiryaev', Springer-Verlag, New York.

Barndorff-Nielsen, O. E. and Shephard, N. (2002a), 'Econometric analysis of realised volatility and its use in stochastic volatility models', Journal of the Royal Statistical Society, Series B 64, 253-280.

Barndorff-Nielsen, O. E. and Shephard, N. (2002b), 'Estimating quadratic variation using realized variance', Journal of Applied Econometrics 17, 457-478.

Barndorff-Nielsen, O. E. and Shephard, N. (2004), 'Power and bipower variation with stochastic and jumps', Journal of Financial Econometrics 2(1), 1-37. Discussion by Torben G. Andersen, 37-48.

Bekaert, G. and Wu, G. (2000), 'Asymmetric volatility and risk in equity markets', The Review of Financial Studies 13, 1-42.

Black, F. (1976), 'Studies of stock price volatility changes', Proceedings of the 1976 Meetings of the American Statistical Association, Business and Economic Statistics pp. 177-181.

Blair, B. J., Poon, S. and Taylor, S. (2001), 'Forecasting S\&P 100 volatility: The incremental information content of implied volatilities and high-frequency index returns', Journal of Econometrics 105, 5-26.

Bollerslev, T., Kretschmer, U., Pigorsch, C. and Tauchen, G. (2009), 'A discrete-time model for daily S\&P500 returns and realized variations: Jumps and leverage effects', Journal of Econometrics 150, 151-166.

Bollerslev, T., Litvinova, J. and Tauchen, G. (2006), 'Leverage and volatility feedback effects in highfrequency data', Journal of Financial Econometrics 4(3), 353-384.

Bollerslev, T., Sizova, N. and Tauchen, G. (2009), Volatility in equilibrium: Asymmetries and dynamic dependencies, Technical report, Department of Economics, Duke University.

Bollerslev, T., Tauchen, G. and Zhou, H. (2009), 'Expected stock returns and variance risk premia', The Review of Financial Studies 22(11), 4463-4492.

Bollerslev, T. and Zhou, H. (2005), 'Volatility puzzles: A unified framework for gauging return-volatility regressions', Journal of Econometrics 131, 123-150.

Bouchaud, J.-P., Matacz, A. and Potters, M. (2001), 'Leverage effect in financial markets: The retarded volatility model', Physical Review Letters 87, 228701.

Brandt, M. W. and Kang, Q. (2004), 'On the relationship between the conditional mean and volatility of stock returns: A latent VAR approach', Journal of Financial Economics 72, 217-257. 
Bunge, M. (1979), Causality and Modern Science, Third Revised Edition, Dover Publications, New York.

Busch, T. B., Christensen, J. and Nielsen, М. Ø. (2010), 'The role of implied volatility in forecasting future realized volatility and jumps in foreign exchange, stock, and bond markets', Journal of Econometrics forthcoming .

Campbell, J. and Hentschel, L. (1992), 'No news is good news: An asymmetric model of changing volatility in stock returns', Journal of Financial Economics 31, 281-331.

Canina, L. and Figlewski, S. (1993), 'The informational content of implied volatility', Review of Financial Studies 6, 659-681.

Carnap, R. (1966), Philosophical Foundations of Physics: An Introduction to the Philosophy of Science, Basic Books, New York.

Chen, X. and Ghysels, E. (2010), 'News - good or bad - and its impact on volatility predictions over multiple horizons', Review of Financial Studies forthcoming .

Christie, A. (1982), 'The stochastic behavior of common stock variances- value, leverage and interest rate effects', Journal of Financial Economics 3, 145-166.

Comte, F. and Renault, E. (1998), 'Long memory in continuous time stochastic volatility models', Mathematical Finance 8, 291-323.

Corsi, F. (2009), 'A simple approximate long-memory model of realized volatility', Journal of Financial Econometrics 7, 174-196.

Day, T. E. and Lewis, C. (1992), 'Stock market volatility and the information content of stock index options', Journal of Econometrics 52, 267-287.

Dennis, P., Mayhew, S. and Stivers, C. (2006), 'Stock returns, implied volatility innovations, and the asymmetric volatility phenomenon', Journal of Financial and Quantitative Analysis 41, 381-406.

Drechsler, I. and Yaron, A. (2010), 'What's vol got to do with it', Review of Financial Studies forthcoming.

Dufour, J.-M., Garcia, R. and Taamouti, A. (2010), Measuring causality between volatility and returns with high-frequency data: Empirical appendix, Technical report, Department of Economics, McGill University, Montréal, Canada.

Dufour, J.-M., Pelletier, D. and Renault, É. (2006), 'Short run and long run causality in time series: Inference', Journal of Econometrics 132(2), 337-362.

Dufour, J.-M. and Renault, E. (1998), 'Short-run and long-run causality in time series: Theory', Econometrica 66, 1099-1125. 
Dufour, J.-M. and Taamouti, A. (2010), 'Short and long run causality measures: Theory and inference', Journal of Econometrics 154, 42-58.

Eells, E. (1991), Probabilistic Causality, Cambridge University Press, Cambridge.

Efron, B. and Tibshirani, R. J. (1993), An Introduction to the Bootstrap, Vol. 57 of Monographs on Statistics and Applied Probability, Chapman \& Hall, New York.

Engle, R. F. and Ng, V. K. (1993), 'Measuring and testing the impact of news on volatility', Journal of Finance 48, 1749-1778.

Fama, E. F. and French, K. R. (1988), 'Permanent and temporary components of stock prices', Journal of Political Economy 96, 246-273.

Feigl, H. (1953), Notes on causality, in H. Feigl and M. Brodbeck, eds, 'Readings in the Philosophy of Science', Appleton-Century-Crofts, Inc., New York.

Fleming, J. (1998), 'The quality of market volatility forecasts implied by S\&P 100 index option prices', Journal of Empirical Finance 5, 317-345.

French, K. R., Schwert, G. W. and Stambaugh, R. F. (1987), 'Expected stock returns and volatility', Journal of Financial Economics 19, 3-30.

Ghysels, E., Santa-Clara, P. and Valkanov, R. (2002), The MIDAS touch: Mixed data sampling regression, Technical report, Department of Economics, University of North Carolina, Chapel-Hill, North Carolina.

Ghysels, E., Santa-Clara, P. and Valkanov, R. (2004), 'There is a risk-return trade-off after all', Journal of Financial Economics 76, 509-548.

Giot, P. (2005), 'Relationships between implied volatility indices and stock index returns', Journal of Portfolio Management 31, 92-100.

Glosten, L. R., Jagannathan, R. and Runkle, D. E. (1993), 'On the relation between the expected value and the volatility of the nominal excess return on stocks', Journal of Finance 48, 1779-1801.

Gonçalves, S. and Kilian, L. (2004), 'Bootstrapping autoregressions in the presence of conditional heteroskedasticity of unknown form', Journal of Econometrics 123, 89-120.

Gouriéroux, C. and Monfort, A. (1992), 'Qualitative threshold ARCH models', Journal of Econometrics 52, 159-199.

Granger, C. W. J. (1969), 'Investigating causal relations by econometric models and cross-spectral methods', Econometrica 37, 424-459. 
Guo, H. and Savickas, R. (2006), 'Idiosyncratic volatility, stock market volatility, and expected stock returns', Journal of Business and Economic Statistics 24(1), 43-56.

Hardouvelis, G. A. (1987), 'Macroeconomic information and stock prices', Journal of Economics and Business 39, 131-140.

Haugen, A. H., Talmor, E. and Torous, W. N. (1991), 'The effect of volatility changes on the level of stock prices and subsequent expected returns', Journal of Finance 46, 985-1007.

Huang, X. (2007), Macroeconomic news announcements, financial market volatility and jumps, Technical report, Department of Economics, Duke University, Durham, North Carolina.

Huang, X. and Tauchen, G. (2005), 'The relative contribution of jumps to total price variance', Journal of Financial Econometrics 3(4), 456-499.

Hume, D. (1748), An Inquiry Concerning Human Understanding, London.

Inoue, A. and Kilian, L. (2002), 'Bootstrapping smooth functions of slope parameters and innovation variances in $V A R(\infty)$ models', International Economic Review 43(2), 309-332.

Jacquier, E., Polson, N. G. and Rossi, P. (2004), 'Bayesian analysis of stochastic volatility models with fat-tails and correlated errors', Journal of Econometrics 122, 185-212.

Jain, P. C. (1988), 'Response of hourly stock prices and trading volume to economic news', The Journal of Business 61, 219-231.

Lamoureux, C. G. and Lastrapes, W. D. (1993), 'Forecasting stock-return variance: Toward an understanding of stochastic implied volatilities', Review of Financial Studies 6, 293-326.

Linton, O. and Mammen, E. (2005), 'Estimating semiparametric $\mathrm{ARCH}(\infty)$ models by kernel smoothing methods', Econometrica 73(3), 735-765.

Ludvigson, S. C. and Ng, S. (2005), 'The empirical risk-return relation: A factor analysis approach', Journal of Financial Economics 83, 171-222.

Masset, P. and Wallmeier, M. (2010), 'A high-frequency investigation of the interaction between volatility and DAX returns', European Financial Management 16(3), 327-344.

McCloskey, D. N. and Ziliak, S. T. (1996), 'The standard error of regressions', The Journal of Economic Literature XXXIV, 97-114.

McQueen, G. and Roley, V. V. (1993), 'Stock prices, news, and business conditions', The Review of Financial Studies 6, 683-707. 
Meddahi, N. (2002), 'A theoretical comparison between integrated and realized volatility', Journal of Applied Econometrics 17, 475-508.

Müller, U., Dacorogna, M., Davé, R., Olsen, R., Pictet, O. and Von Weizsäcker, J. (1997), 'Volatilities of different time resolutions - analyzing the dynamics of market components', Journal of Empirical Finance 4, 213-39.

Nelson, D. B. (1991), 'Conditional heteroskedasticity in asset returns: A new approach', Econometrica 59, 347-370.

Pagan, A. R. and Schwert, G. W. (1990), 'Alternative models for conditional stock volatility', Journal of Econometrics 45, 267-290.

Pan, J. (2002), 'The jump-risk premia implicit in options: Evidence from an integrated time-series study', Journal of Financial Economics 63, 3-50.

Pearce, D. K. and Roley, V. V. (1985), 'Stock prices and economic news', Journal of Business 58, 49-67.

Pearl, J. (2000), Causality: Models, Reasoning, and Inference, Cambridge University Press, Cambridge, U.K.

Pindyck, R. S. (1984), 'Risk, inflation, and the stock market', American Economic Review 74, 334-351.

Poteshman, A. M. (2000), Forecasting future volatility from option prices, Technical report, Department of Finance, University of Illinois at Urbana-Champaign, Champaign, Illinois.

Salmon, W. C. (1984), Scientific Explanation and the Causal Structure of the World, Princeton University Press, Princeton (N.J.).

Schwert, G. W. (1981), 'The adjustment of stock prices to information about inflation', Journal of Finance 36, 15-29.

Schwert, G. W. (1989), 'Why does stock market volatility change over time?', Journal of Finance 44, 11151153.

Sosa, E. and Tooley, M., eds (1993), Causation, Oxford University Press, Oxford, U.K.

Spirtes, P., Glymour, C. and Scheines, R. (1993), Causation, Prediction, and Search, Vol. 81 of Lecture Notes in Statistics, Springer-Verlag, New York.

Turner, C. M., Startz, R. and Nelson, C. R. (1989), 'A Markov model of heteroskedasticity, risk and learning in the stock market', Journal of Financial Economics 25, 3-22.

Whaley, R. (2000), 'The investor fear gauge', Journal of Portfolio Management 26, 12-17. 
Whitelaw, R. F. (1994), 'Time variations and covariations in the expectation and volatility of stock market returns', The Journal of Finance 49(2), 515-41.

Wiener, N. (1956), The theory of prediction, in E. F. Beckenback, ed., 'The Theory of Prediction', McGrawHill, New York, chapter 8.

Wiggins, J. B. (1987), 'Option values under stochastic volatilities', Journal of Financial Economics 19, 351372.

\section{Appendix}

In this appendix, we report in tables some basic summary statistics which can be useful for interpreting the empirical results presented in this paper [tables 1 and 2] some basic descriptive statistics, which can be useful for interpreting the empirical results, as well as tables and graphs that summarize our main findings. Additional details and complementary results are available in a separate companion document [Dufour et al. (2010)].

\section{A. Descriptive statistics}

Table 1. Summary statistics for S\&P 500 futures returns, 1988-2005

\begin{tabular}{|l|l|l|l|l|l|}
\hline Variables & Mean & St.Dev. & Median & Skewness & Kurtosis \\
\hline Five-minute & 0.0000069 & 0.000978 & 0.00000000 & -0.0818 & 73.9998 \\
Hourly & 0.0000131 & 0.003100 & 0.00000000 & -0.4559 & 16.6031 \\
Daily & 0.0001466 & 0.008900 & 0.00011126 & -0.1628 & 12.3714 \\
\hline
\end{tabular}

Note: This table summarizes the five-minute, hourly, and daily returns distributions for the S\&P 500 index contracts.

Table 2. Summary statistics for hourly and daily volatilities, 1988-2005

\begin{tabular}{|l|l|l|l|l|l|}
\hline Variables & Mean & St.Dev. & Median & Skewness & Kurtosis \\
\hline Hourly & & & & & \\
$R V_{t}$ & 0.00001080 & 0.0000294 & 0.00000544 & 42.9510 & 3211.190 \\
$B V_{t}$ & 0.00000932 & 0.0000229 & 0.00000455 & 32.1242 & 2023.507 \\
$\ln \left(R V_{t}\right)$ & -12.2894 & 1.1475 & -12.3006 & 0.0792 & 3.3157 \\
$\ln \left(B V_{t}\right)$ & -12.1007 & 1.0973 & -12.1217 & 0.1558 & 3.2625 \\
$J_{t+1}$ & 0.2258 & 0.2912 & 0.1221 & 2.0066 & 8.8949 \\
& & & & & \\
Daily & & & & & \\
$R V_{t}$ & 0.0000813 & 0.000120 & 0.0000498 & 8.1881 & 120.7530 \\
$B V_{t}$ & 0.0000762 & 0.000109 & 0.0000469 & 6.8789 & 78.9491 \\
$\ln \left(R V_{t}\right)$ & -9.8582 & 0.8762 & -9.9076 & 0.4250 & 3.3382 \\
$\ln \left(B V_{t}\right)$ & -9.9275 & 0.8839 & -9.9663 & 0.4151 & 3.2841 \\
$J_{t+1}$ & 0.0870 & 0.1005 & 0.0575 & 1.6630 & 7.3867 \\
\hline
\end{tabular}

Note: This table summarizes the hourly and daily volatilities distributions for the S\&P 500 index contracts. 
Table 3. Summary statistics for daily implied volatilities, 1996-2005

\begin{tabular}{|l|l|l|l|l|l|}
\hline Variables & Mean & St.Dev. & Median & Skewness & Kurtosis \\
\hline$I V_{t}^{1 / 2}$ & 1.1808 & 0.8225 & 1.0205 & 3.4518 & 30.5778 \\
$I V_{t}$ & 2.0705 & 5.1356 & 1.0415 & 17.8220 & 484.6803 \\
$\ln \left(I V_{t}\right)$ & -0.0326 & 1.1980 & 0.0406 & 0.0676 & 3.0002 \\
\hline
\end{tabular}

Note: This table summarizes the daily implied volatilities distributions for the S\&P 500 index contracts.

\section{B. Summary of causality measures}

Table 4. Hourly and daily volatility feedback effects

Hourly volatility feedback effects using $\ln (R V)$

\begin{tabular}{|l|l|l|l|l|}
\hline$C(\ln (R V) \underset{h}{\rightarrow} r)$ & $h=1$ & $h=2$ & $h=3$ & $h=4$ \\
\hline Point estimate & 0.00016 & 0.00014 & 0.00012 & 0.00012 \\
\hline 95\% Bootstrap interval & {$[0.0000,0.0007]$} & {$[0.0000,0.0006]$} & {$[0.0000,0.0005]$} & {$[0.0000,0.0005]$} \\
\hline
\end{tabular}

Hourly volatility feedback effects using $\ln (B V)$

\begin{tabular}{|l|l|l|l|l|}
\hline$C(\ln (B V) \underset{h}{ } r)$ & $h=1$ & $h=2$ & $h=3$ & $h=4$ \\
\hline Point estimate & 0.00022 & 0.00020 & 0.00019 & 0.00015 \\
\hline 95\% Bootstrap interval & {$[0.0000,0.0008]$} & {$[0.0000,0.0007]$} & {$[0.0000,0.0007]$} & {$[0.0000,0.0005]$} \\
\hline
\end{tabular}

Daily volatility feedback effects using $\ln (R V)$

\begin{tabular}{|l|l|l|l|l|}
\hline$C(\ln (R V) \underset{h}{\rightarrow} r)$ & $h=1$ & $h=2$ & $h=3$ & $h=4$ \\
\hline Point estimate & 0.0019 & 0.0019 & 0.0019 & 0.0011 \\
\hline 95\% Bootstrap interval & {$[0.0007,0.0068]$} & {$[0.0005,0.0065]$} & {$[0.0004,0.0061]$} & {$[0.0002,0.0042]$} \\
\hline
\end{tabular}

Daily volatility feedback effects using $\ln (B V)$

\begin{tabular}{|l|l|l|l|l|}
\hline$C(\ln (B V) \underset{h}{\rightarrow} r)$ & $h=1$ & $h=2$ & $h=3$ & $h=4$ \\
\hline Point estimate & 0.0017 & 0.0017 & 0.0016 & 0.0011 \\
\hline $95 \%$ Bootstrap interval & {$[0.0007,0.0061]$} & {$[0.0005,0.0056]$} & {$[0.0004,0.0055]$} & {$[0.0002,0.0042]$} \\
\hline
\end{tabular}

Note: This table summarizes the estimation results of causality measures from hourly realized volatility $[\ln (R V)]$ to hourly returns $(r)$, hourly bipower variation $[\ln (B V)]$ to hourly returns, daily realized volatility to daily returns, and daily bipower variation to daily returns, respectively. The second row in each small table gives the point estimate of the causality measures at horizons $h=1, \ldots, 4$. The third row gives the $95 \%$ corresponding percentile bootstrap interval. 
Figure 1. Quantile to quantile plots (QQ plot) of the relative measure of jumps $(R J), z_{Q P, l, t}, z_{Q P, t}$, and $z_{Q P, l m, t}$. January 1988 to December 2005.
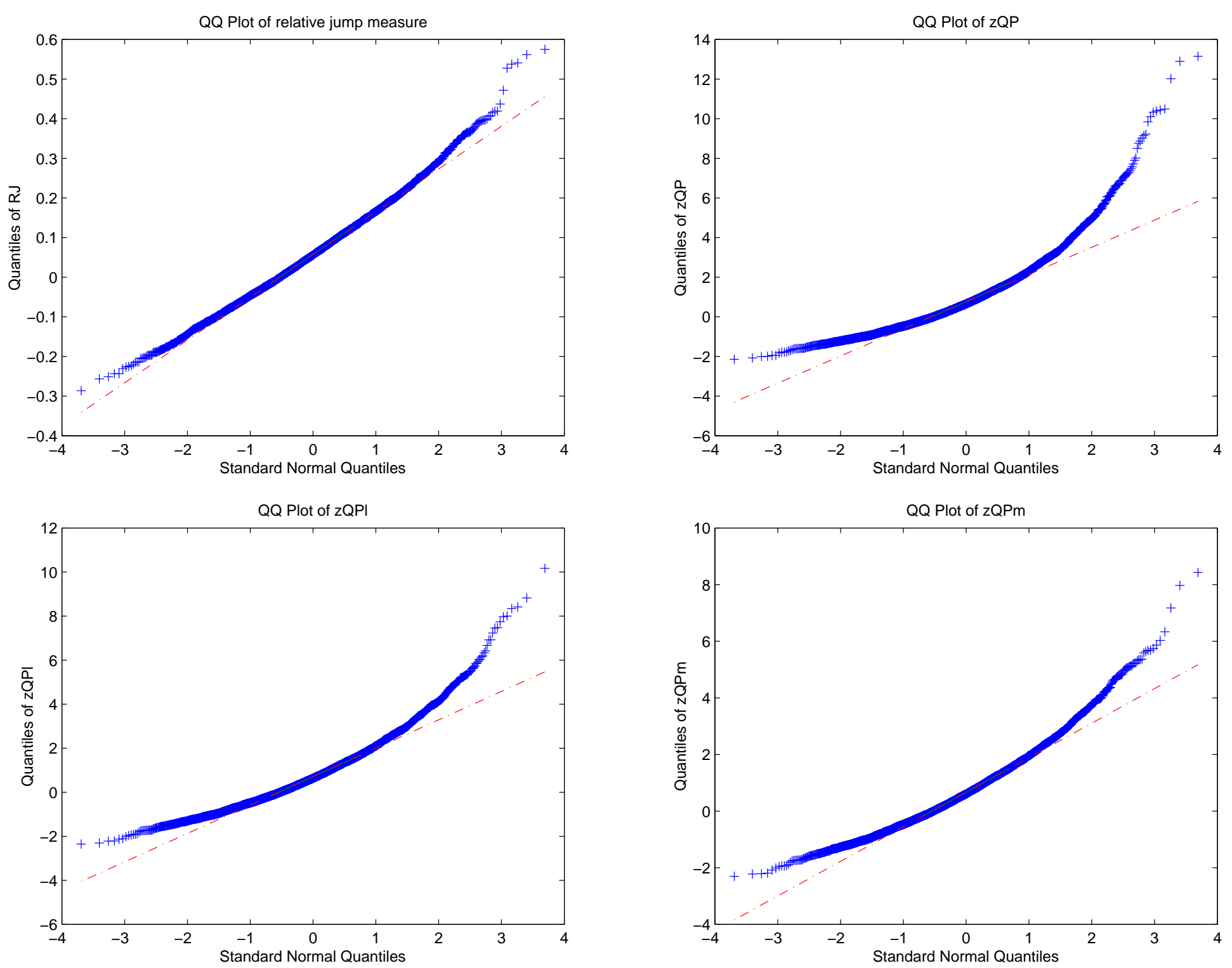
Table 5. Measuring the impact of good news on volatility using $\ln (R V)$ [centered positive returns]

\begin{tabular}{|c|c|c|c|c|}
\hline \multicolumn{5}{|c|}{$\widehat{\mathrm{E}_{t}\left(r_{t+1}\right)}=\frac{1}{15} \sum_{j=1}^{15} r_{t+1-j}$} \\
\hline$C\left(e r^{+} \rightarrow \ln (R V)\right)$ & $h=1$ & $h=2$ & $h=3$ & $h=4$ \\
\hline Point estimate & 0.0007 & 0.0007 & 0.0007 & 0.0004 \\
\hline $95 \%$ Percentile bootstrap interval & {$[0.0003,0.0043]$} & {$[0.0002,0.0039]$} & {$[0.0001,0.0034]$} & {$[0.0000,0.0030]$} \\
\hline \multicolumn{5}{|c|}{$\widehat{\mathrm{E}_{t}\left(\widehat{r_{t+1}}\right)}=\frac{1}{30} \sum_{j=1}^{30} r_{t+1-j}$} \\
\hline$C\left(e r^{+} \underset{h}{\rightarrow} \ln (R V)\right)$ & $h=1$ & $h=2$ & $h=3$ & $h=4$ \\
\hline Point estimate & 0.0010 & 0.0007 & 0.0007 & 0.0005 \\
\hline 95\% Percentile bootstrap interval & {$[0.0004,0.0051]$} & {$[0.0003,0.0039]$} & {$[0.0003,0.0036]$} & {$[0.0000,0.0032]$} \\
\hline
\end{tabular}

Note: This table summarizes the estimation results of causality measures from centered positive returns $\left(e r^{+}\right)$to realized volatility $[\ln (R V)]$ using two estimators of the conditional mean, for $m=15,30$. In each of the two small tables, the second row gives the point estimate of the causality measures at horizons $h=1, \ldots, 4$. The third row gives the $95 \%$ corresponding percentile bootstrap interval.

Table 6. Measuring the impact of good news on volatility using $\ln (B V)$ [centered positive returns]

\begin{tabular}{|c|c|c|c|c|}
\hline$C\left(e r^{+} \underset{h}{\rightarrow} \ln (B V)\right)$ & $h=1$ & $h=2$ & $h=3$ & $h=4$ \\
\hline Point estimate & 0.0008 & 0.0008 & 0.0006 & 0.0006 \\
\hline $95 \%$ Percentile bootstrap interval & {$[0.0003,0.0045]$} & {$[0.0002,0.0041]$} & {$[0.0002,0.0035]$} & {$[0.0000,0.0034]$} \\
\hline \multicolumn{5}{|c|}{$\widehat{\mathrm{E}_{t}\left(r_{t+1}\right)}=\frac{1}{30} \sum_{j=1}^{30} r_{t+1-j}$} \\
\hline$C\left(e r^{+} \rightarrow \ln (B V)\right)$ & $h=1$ & $h=2$ & $h=3$ & $h=4$ \\
\hline Point estimate & 0.0012 & 0.0007 & 0.0007 & 0.0007 \\
\hline $95 \%$ Percentile bootstrap interval & {$[0.0005,0.0053]$} & {$[0.0003,0.0041]$} & {$[0.0002,0.0039]$} & {$[0.0001,0.0038]$} \\
\hline
\end{tabular}

Note: This table summarizes the estimation results of causality measures from centered positive returns $\left(e r^{+}\right)$to bipower variation [ln $\left.(B V)\right]$ using two estimators of the conditional mean, for $m=15,30$. In each of the two small tables, the second row gives the point estimate of the causality measures at horizons $h=1, \ldots, 4$. The third row gives the $95 \%$ corresponding percentile bootstrap interval. 
Figure 2. Leverage and volatility feedback effects in hourly and daily data using a bivariate autoregressive model $(r, R V)$. January 1988 to December 2005.
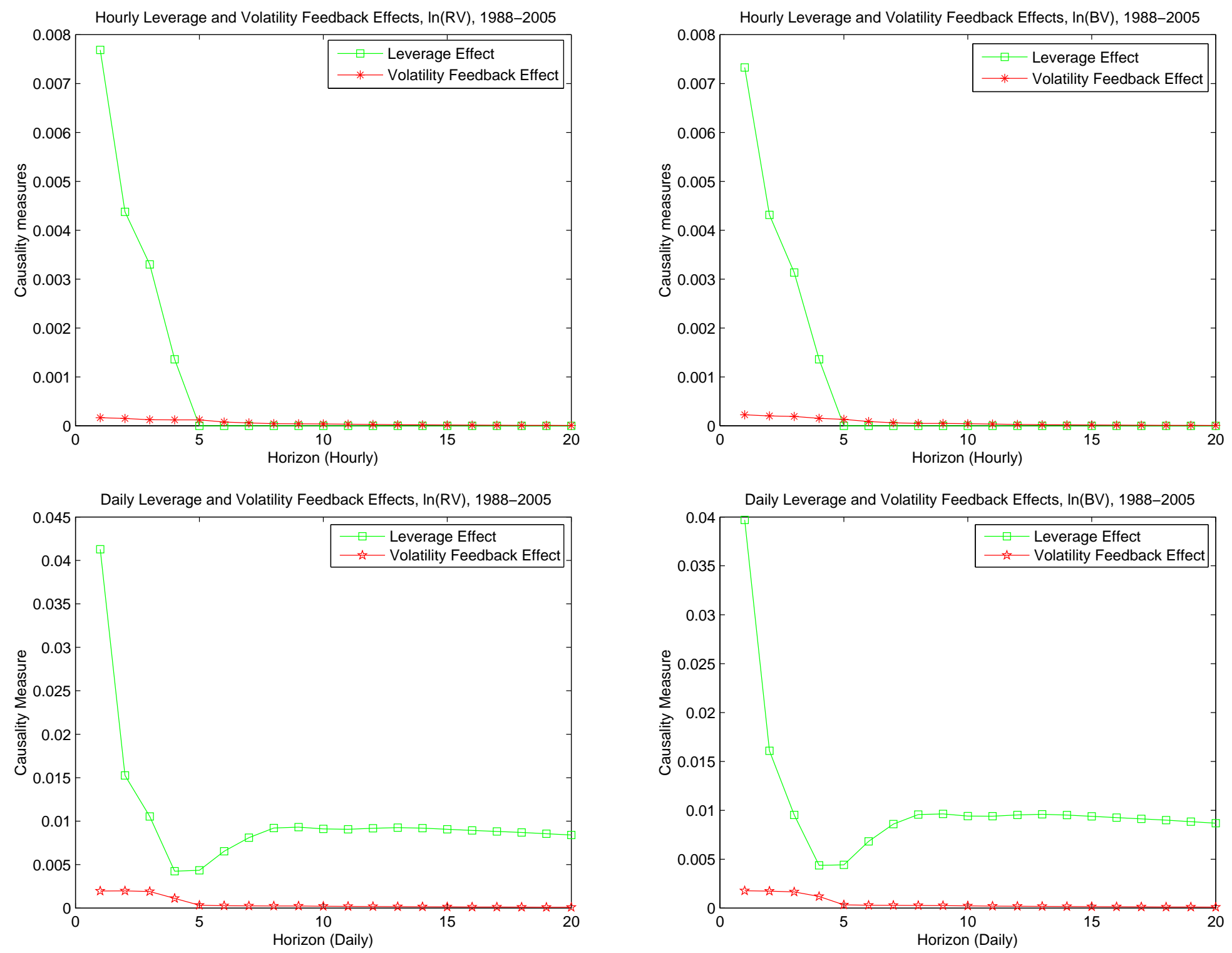
Figure 3. Causality measures between implied volatility $(I V)$ [or variance risk premium $I V-R V$ ] and realized volatility $(R V)$, using trivariate VAR models for $(r, R V, I V)$ and $(r, R V, I V-R V)$. January 1996 to December 2005.
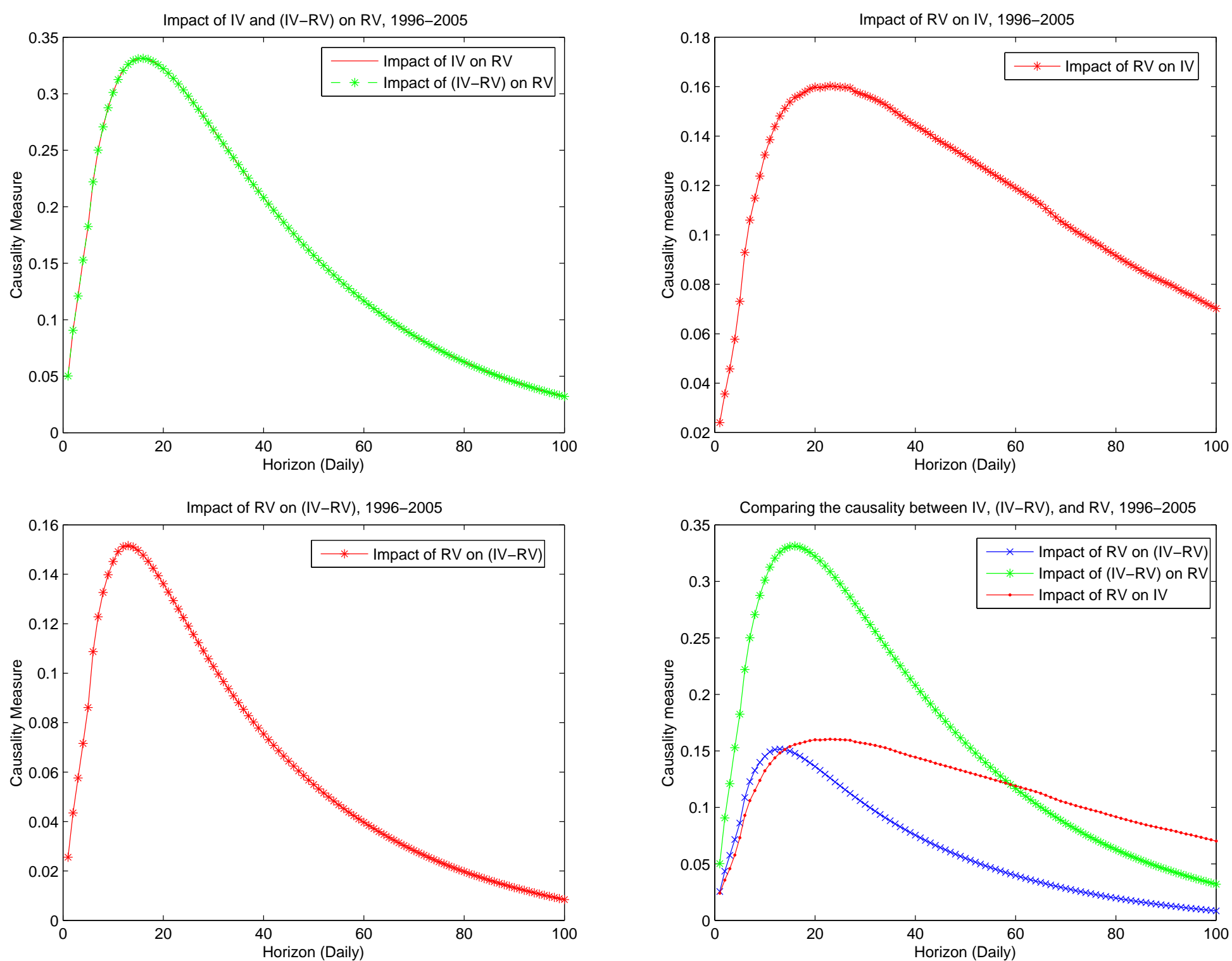
Figure 4. Volatility feedback effects, with implied volatility as auxiliary variable [trivariate models $(r, R V, I V)$ and $(r, R V, I V-R V)]$ and without implied volatility [bivariate model $(r, R V)]$; different transformations of volatility considered. Impact of vector $(R V, I V-R V)$ on returns. January 1996 to December 2005.
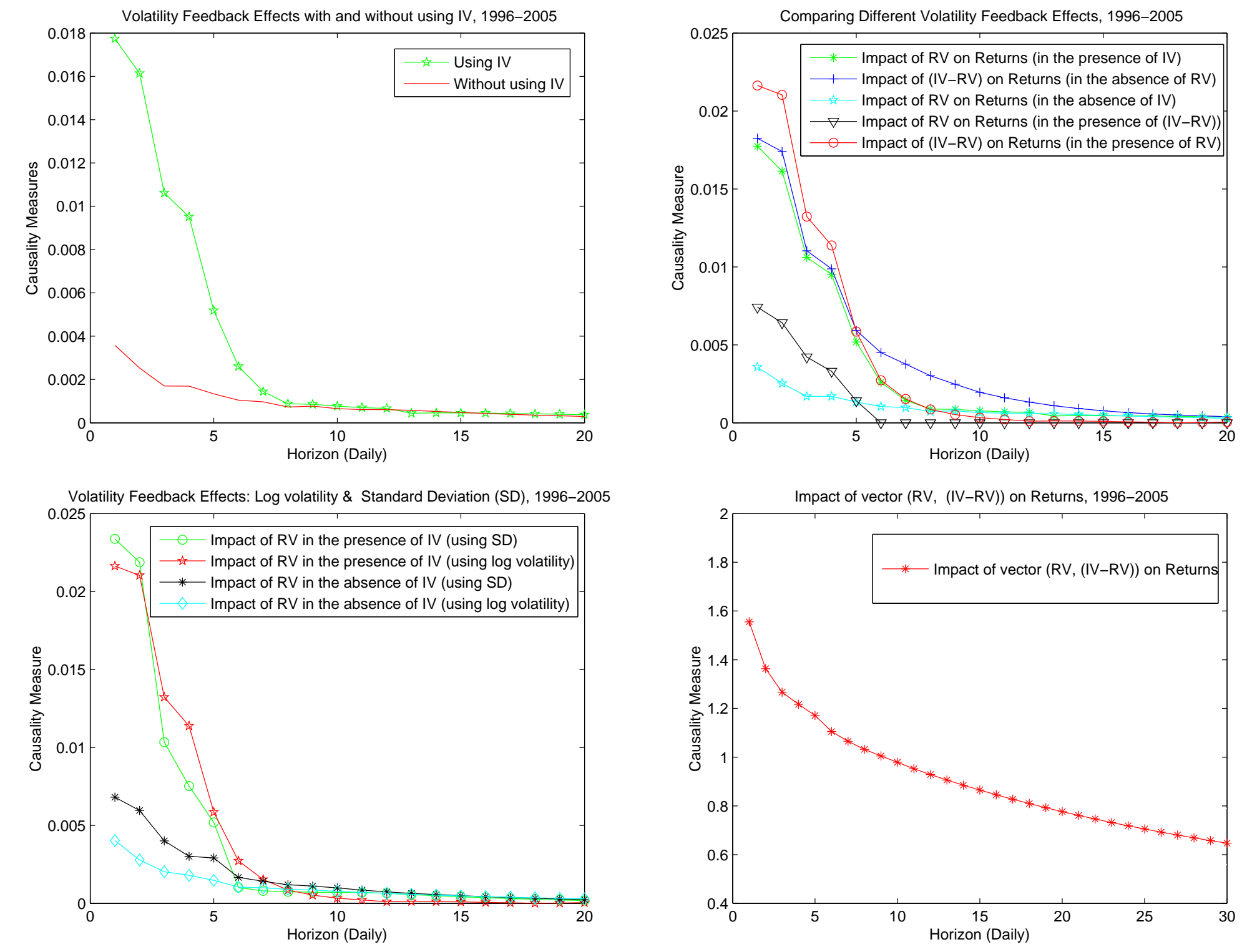
Figure 5. Leverage and volatility feedback effects, with implied volatility as auxiliary variable [trivariate models $(r, R V, I V)$ and $(r, R V, I V-R V)]$ and without implied volatility [bivariate model $(r, R V)$ ]. January 1996 to December 2005.
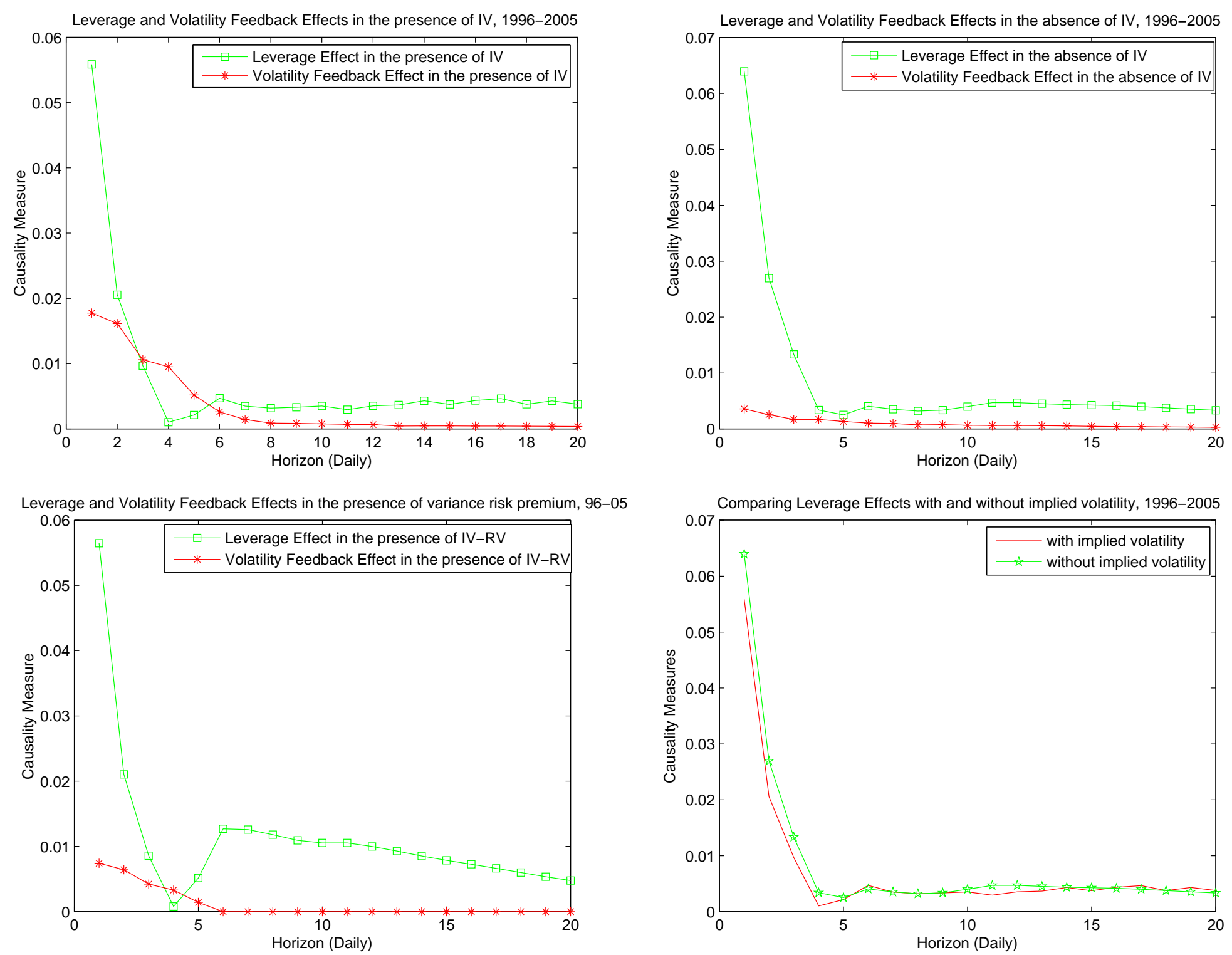
Figure 6. Causality measures of the impact of bad and good news on symmetric and asymmetric GARCH volatility models.
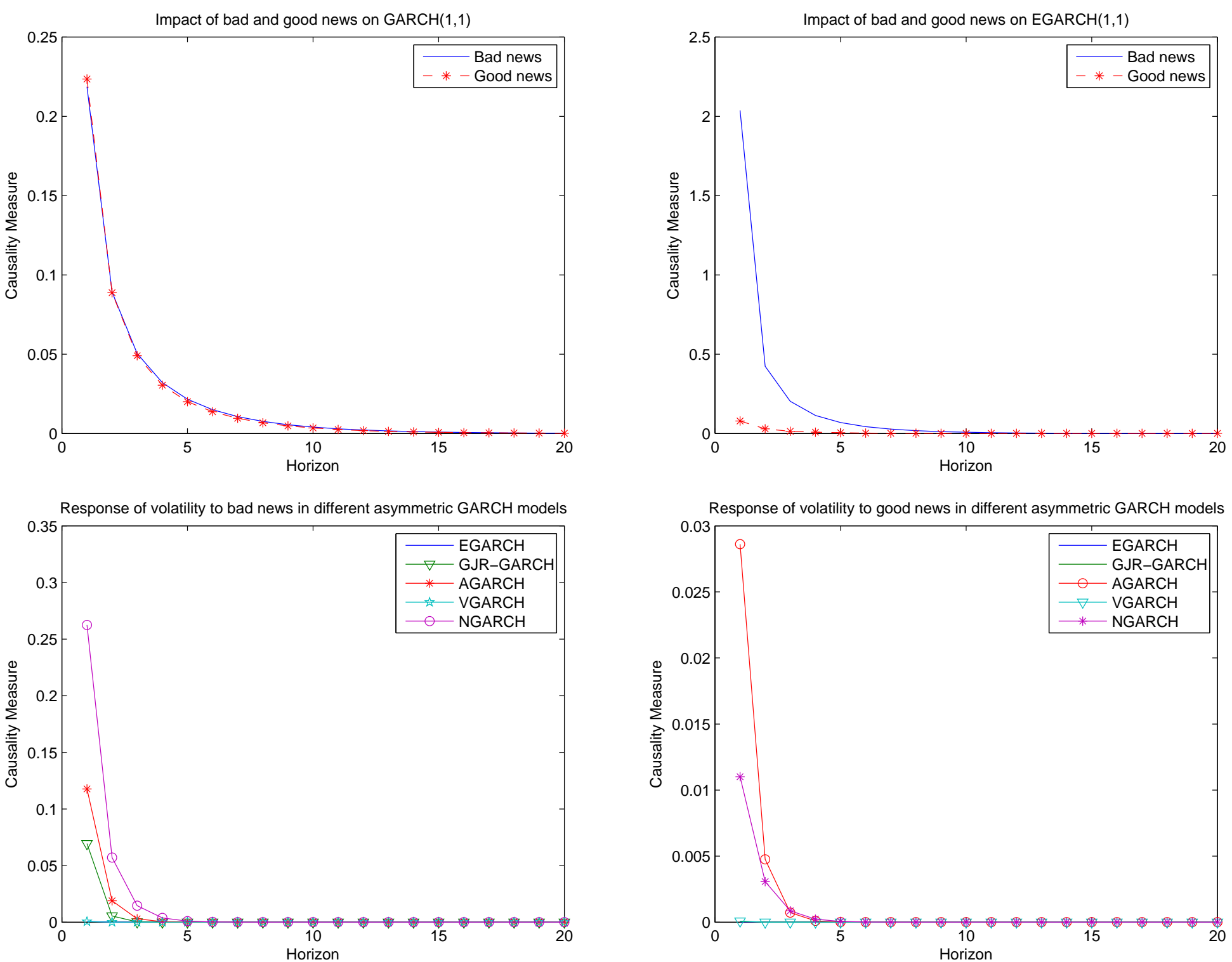
Figure 7. Causality measures of the impact of bad and good news on volatility and the impact of positive and negative variance risk premium on returns. January 1988 to December 2005.
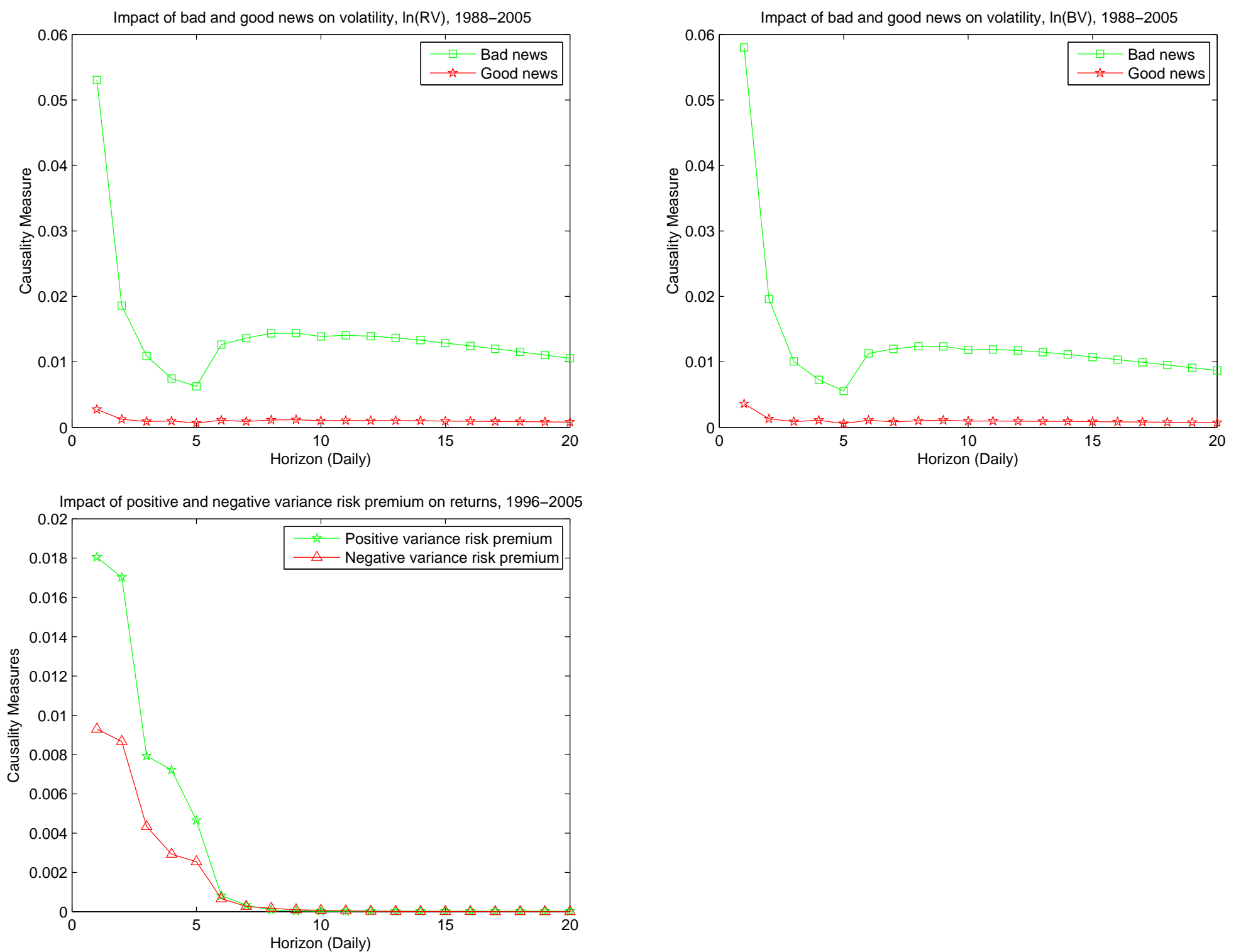